Published in final edited form as:

Nat Rev Cancer. ; 11(8): 573-587. doi:10.1038/nrc3078.

\title{
Chemotaxis in cancer
}

\author{
Evanthia T. Roussos, John S. Condeelis, and Antonia Patsialou \\ Department of Anatomy and Structural Biology, Program in Tumor Microenvironment and \\ Metastasis, Albert Einstein College of Medicine of Yeshiva University, Bronx, New York 10461, \\ USA
}

\section{Abstract}

Chemotaxis of tumour cells and stromal cells in the surrounding microenvironment is an essential component of tumour dissemination during progression and metastasis. This Review summarizes how chemotaxis directs the different behaviours of tumour cells and stromal cells in vivo, how molecular pathways regulate chemotaxis in tumour cells and how chemotaxis choreographs cell behaviour to shape the tumour microenvironment and to determine metastatic spread. The central importance of chemotaxis in cancer progression is highlighted by discussion of the use of chemotaxis as a prognostic marker, a treatment end point and a target of therapeutic intervention.

Chemotaxis is the phenomenon by which the movement of cells is directed in response to an extracellular chemical gradient. Over 100 years of research have illustrated the importance of chemotaxis in physiological processes, such as the recruitment of inflammatory cells to sites of infection, and in organ development during embryogenesis. In cancer, chemotaxis pathways can be reprogrammed in favour of tumour cell dissemination ${ }^{1}$. To successfully metastasize, a carcinoma cell must invade, intravasate, extravasate and grow at a distant site. Chemotaxis is thought to be involved in each of these crucial steps of tumour cell dissemination. Chemotaxis of carcinoma cells and tumour-associated inflammatory and stromal cells is mediated by chemokines, chemokine receptors, growth factors and growth factor receptors (TABLE 1 and Supplementary information S1 (table)). Mutation and/or changes in the regulation of many of these factors are frequently involved in the development and progression of various types of cancer. Although most of these factors have roles in the growth and survival of tumour and stromal cells, their downstream signalling cascades can also lead to changes in cytoskeletal dynamics that result in chemotaxis. This suggests a potentially important and sometimes overlooked role of chemotaxis in cancer cell dissemination and metastatic progression. The development of new technologies and a burst of interdisciplinary collaboration in the study of chemotaxis in cancer have recently provided valuable insights into novel and specific mechanisms of invasion and dissemination and have ignited much hope for new prognostic tools and therapeutic interventions. In this Review, we discuss the role of chemotaxis in cancer cell

(C) 2011 Macmillan Publishers Limited. All rights reserved

Correspondence to: J.S.C. and A.P. john.condeelis@einstein.yu.edu; antonia.patsialou@einstein.yu.edu.

Competing interests statement

The authors declare competing financial interests: see Web version for details. 
dissemination and discuss whether chemotaxis is a viable marker for treatment decisions and a target for cancer therapy.

\section{Chemotaxis and cell migration}

Cell migration is an essential component of metastatic dissemination of tumour cells from the primary tumour to local and distant $\operatorname{sites}^{2-4}$. Although tumour cells can move both randomly and directionally, invasion, migration and dissemination are most efficient when the cell is involved in directed migration ${ }^{5}$. Different types of directed cell migration have been observed in tumour cells: chemotaxis, haptotaxis, electrotaxis and durotaxis ${ }^{6}$. The location and type of cue theoretically determines which of these types of directed cell migration is engaged. For example, directed migration towards a soluble chemotactic agent is traditionally called chemotaxis, migration towards a substrate-bound agent is called haptotaxis and migration that is influenced by an extracellular matrix (ECM) rigidity gradient is called durotaxis ${ }^{7}$.

Although the shape and amplitude of a soluble chemotactic gradient delivered experimentally in vitro can be defined with precision ${ }^{8-11}$, current technology does not allow the distinction of chemotaxis in vivo towards soluble factors from chemotaxis towards factors partially or fully bound to the ECM and/or cell surfaces. For example, in vitro binding studies indicate that cytokines can become immobilized to form solid state gradients, which suggests that both soluble and solid state gradients might contribute to chemotaxis in vivo ${ }^{12}$. However, because it is not possible to know whether a gradient is soluble or solid state when observing cell behaviour in vivo, for the purposes of this Review, we define chemotaxis in vivo as directional migration to either soluble or solid state gradients.

Chemotaxis is the result of three separate steps: chemosensing, polarization and locomotion ${ }^{13}$. Depending on the cell type and the microenvironment, migration can involve single unattached cells or multicellular groups (TABLE 2). Directed migration of single tumour cells can be subdivided into either amoeboid migration or mesenchymal migration. Directed multicellular migration can be subdivided into either collective migration, in which the cells are in tight contact with each other (also known as cohort migration) or cell streaming, in which the coordinated cell migration involves cells that are not always in direct physical contact. The occurrence and frequency of these different modes of migration in cancer is dependent on the tumour type and the types of cells and surrounding factors in the tumour microenvironment ${ }^{14,15}$ (TABLE 2). Various methods have been used to study in detail the different modes of migration in cancer, including cultured cells in vitro ${ }^{16}$, threedimensional cultures with cells embedded in reconstituted ECM gels ${ }^{17-19}$ and intravital multiphoton microscopy of live animals $s^{4,20-22}$ (TABLE 3).

Amoeboid migration of single tumour cells has been observed in tumours in vivo by intravital multiphoton imaging. Such studies have shown that some carcinoma cells with an amoeboid morphology can move at high speeds inside the tumours $\left(\sim 4 \mu \mathrm{min}^{-1}\right)^{4}$. Amoeboid cell motility does not always require the activity of matrix metalloproteinases (MMPs) because cells can squeeze through gaps in the ECM by generating large amounts of 
contractile force ${ }^{23,24}$. At the other end of the range of modes of motility, mesenchymal migration of single cells, which sometimes involves collective migration, is characterized by an elongated cell morphology with established cell polarity and relatively low speeds of cell migration $\left(0.1-1 \mu \mathrm{m} \mathrm{min}^{-1}\right)^{15}$. Tumour cells undergoing epithelial-to-mesenchymal transition (EMT), which is apparent in $10-40 \%$ of carcinomas ${ }^{25}$, can use mesenchymal migration ${ }^{25}$. Mesenchymal cell migration relies on proteolysis of ECM proteins to enable cells to move through the matrix-filled space of the tumour ${ }^{26}$. However, even though amoeboid and mesenchymal modes of migration can be readily separated when studied in vitro, evidence suggests that they are not mutually exclusive in vivo and can interconvert. In tumour cells, responses to changes in the microenvironment can induce rapid transitions between these modes of migration ${ }^{27,28}$. For example, inhibition of proteolysis can promote the transition from mesenchymal to amoeboid migration in tumour cells ${ }^{23}$, whereas enhanced paracrine chemotaxis between tumour cells and stromal cells can cause amoeboid movement in cell streams ${ }^{5}$, suggesting that a combination of treatments that target both proteases and chemotaxis may be needed in the future in order to inhibit tumour cell migration and invasion ${ }^{27}$.

Collective migration has been defined as the movement of whole clusters or sheets of tumour cells that occurs when two or more cells retain cell-cell junctions as they move together through the $\mathrm{ECM}^{22}$. In this mode of migration, leader cells positioned at the front of the migrating group actively participate in chemotaxis and matrix degradation to create tracks ${ }^{29-35}$. Cells positioned further away from the leader cells follow and this may be facilitated by physical coupling to the leader cells by drag forces and by movement along remodelled matrix tracks ${ }^{29-34}$. The leader cell in the case of collective migration can be either a tumour cell with proteolytic activity or a stromal cell from the tumour microenvironment ${ }^{17,36-40}$. For example, in in vitro organotypic models of squamous cell carcinoma (SCC), activated fibroblasts can create tracks in the ECM that enable carcinoma cells to move collectively behind them ${ }^{17}$. Additionally, it has been shown using MadinDarby canine kidney (MDCK) cells that multiple rows of cells behind an epithelial wound edge extend lamellipodia to collectively drive cell sheet movement ${ }^{41}$. In this type of collective migration the cells positioned away from the edge seem to be participating in active migration and chemokine sensing. However, this type of migration has not been documented in tumours. In this regard, it should be noted that multicellular collective migration is a separate phenomenon from multicellular streaming. During streaming, individual cells move and follow each other in the same tracks without the requirement for cell-cell contact or intact junctions ${ }^{5,42-44}$. In a similar way to collective migration, however, cell streaming often involves stromal cells that comigrate with the tumour cells, which may pathfind and/or create tracks by matrix degradation ${ }^{5}$.

Even though tumour cells can display various and sometimes interchangeable patterns of directed migration during tumour cell dissemination, the intracellular processes that direct the cell motility cycle towards a chemoattractant are probably similar. The motility cycle begins with polarized intracellular signals that lead to asymmetric actin polymerization. This results in extension of the cell membrane in the direction of movement, thus creating the leading-edge protrusion. This is followed by integrin-mediated adhesion to the substrate on 
which the cell is moving, and it ends with detachment from the substrate and contraction of the trailing edge of the cell ${ }^{45,46}$. The following section discusses the mechanisms and the signalling pathways that govern these processes and that regulate chemotaxis in tumour cells in particular.

\section{Mechanisms of chemotaxis in tumour cells}

The regulation of chemotaxis has been studied extensively in Dictyostelium discoideum $^{13,46-52}$, mammalian leukocytes ${ }^{53-55}$ and tumour cells ${ }^{8,13,56-66}$. Chemotactic amoeboid migration involves a signal transduction system whereby a dynamic but unpolarized distribution of receptors enables cells to detect chemical gradients ${ }^{48,49,67}$. On receptor activation a series of signalling events leads to an asymmetric cytoskeletal response followed by directed cell migration towards chemotactic cues ${ }^{48,49,58}$. Owing to its genetic tractability, $D$. discoideum has been used to identify about 18 chemokine receptors (members of the G protein-coupled receptor (GPCR) family) for about 50 different chemokines that control chemotaxis ${ }^{48}$. These prototypical studies in $D$. discoideum have influenced the investigation of GPCR signalling pathways controlling chemotaxis in other cell types, such as leukocytes ${ }^{53}$ and tumour cells ${ }^{47,51,68}$. In addition, studies using $D$. discoideum as a model system led to the development of the local excitation-global inhibition (LEGI) model to describe chemotactic amoeboid migration: receptor occupancy by the chemoattractant triggers a fast, local excitatory signal and a slower, global inhibitory signal $^{46}$. The LEGI model, sometimes called the compass model ${ }^{55}$, has made an important contribution to the study of chemotaxis in tumour cells as it can be applied to various signalling pathways in tumour cells. In addition to the characterization of the LEGI model, there are other advantages of studying chemotaxis in D. discoideum (BOX 1). However, careful comparison of $D$. discoideum to vertebrate cells reveals important differences in chemotactic signalling pathways. For example, unlike $D$. discoideum, amoeboid migration of breast tumour cells relies on phosphorylated cofilin signalling pathways, which are not present in $D$. discoideum ${ }^{58,59}$. Thus, signalling regulation that may be important for chemotaxis of tumour cells or other cell types involved in tumour progression and metastasis cannot be fully studied using $D$. discoideum alone ${ }^{48,69,70}$. It is therefore important to study chemotaxis of tumour cells in physiologically relevant cell types and within the tumour microenvironment.

\section{Box 1}

Dictyostelium discoideum: a model organism for the study of chemotaxis

Dictyostelium discoideum depends on efficient motility during its developmental cycle and its vegetative amoeboid stage $\mathrm{e}^{52}$ and provides a model for the study of chemotaxis in the absence of the complexity imposed by the in vivo microenvironment of animals ${ }^{152-154}$. One of its main benefits is that when grown in culture these cells exist as homogenous chemotactic phagocytes ${ }^{48,49}$, which can be grown in high-density suspension cultures to generate kilogram quantities of proteins for biochemical analysis ${ }^{155}$. In a population, physiological responses to chemotactic stimulation are synchronous and can be correlated with biochemical measurements ${ }^{156,157}$. Also, $D$. discoideum is induced by physiological stimuli to undergo normal morphogenesis in 
vitro, which enables the role of chemotaxis in morphogenesis to be studied directly ${ }^{158}$. Recent studies have identified target of rapamycin complex 2 (TORC2) as a common regulator of cell motility in $D$. discoideum and neutrophils ${ }^{159-161}$. Whereas the function of TORC2 differs in $D$. discoideum versus neutrophils in the regulation of actin polymerization, TORC2 has key regulatory functions for controlling cell motility in both cell types ${ }^{160,161}$.

However, differences between $D$. discoideum and mammalian tumour cells have complicated the correlation of findings concerning chemotactic signalling and the understanding of chemotactic behaviour ${ }^{48,53,162}$. For example, there are several redundant signalling pathways controlling chemotaxis in $D$. discoideum ${ }^{47}$ : one is dependent on PI3K and the other is dependent on phospholipase A2 (PLA2) ${ }^{69,163,164}$. Therefore, knockdown of the PI3K pathway in $D$. discoideum results in the incomplete inhibition of chemotaxis ${ }^{93,165-169}$, whereas knockdown of the PI3K pathway in mammalian tumour cells substantially impairs locomotion, an essential step in chemotaxis ${ }^{170}$. Additionally, in tumour cells, the early signal that determines the direction of the leading edge is not PI3K, but involves the epidermal growth factor (EGF)-phospholipase $\mathrm{C} \gamma 1$-cofilin signalling axis ${ }^{59,171}$. D. discoideum also does not express LIM domain kinase 1 (LIMK1), a protein that is required as part of the local excitation-global inhibition (LEGI) system that controls this early signalling cascade to initiate directional sensing during the chemotaxis of tumour cells ${ }^{56}$. In addition, $D$. discoideum exhibits single cell amoeboid chemotaxis and multicellular coordinated cell streaming ${ }^{43,44}$, as well as multicellular collective migration at the slug stage $\mathrm{e}^{48,172}$, but has not yet been shown to exhibit single cell mesenchymal migration. Finally, $D$. discoideum exhibits a default constitutive oscillatory movement pattern in the absence of external signalling molecules ${ }^{172,173}$, whereas tumour cells require repeated stimuli by specific signalling molecules in order to undergo directed cell migration ${ }^{56}$.

A complex network of chemokines has been described as one of the main classes of cues that initiate chemotaxis in tumour cells ${ }^{71}$. In addition to chemotaxis, the chemokine network can regulate processes such as tumour cell growth, angiogenesis, immune evasion, senescence, survival, invasion and metastatic progression ${ }^{72-74}$. Over 50 different chemokines and chemokine receptors are now known to be involved in cancer and approximately $30 \%$ of these are also important for chemotaxis (TABLE 1). One of the most widely studied examples is the chemokine receptor CXCR4 and its ligand CXCL12 (also known as SDF1), which have been found to initiate both single cell and multicellular directed migration during metastatic progression in 11 different types of cancer ${ }^{75-77}$. Another major category of cues that has been shown to have an important role in chemotaxis is growth factors. One of the most studied growth factors involved in tumour cell chemotaxis, particularly in breast cancer, is epidermal growth factor (EGF). Signalling through either a chemokine receptor (a GPCR) or a growth factor receptor (a receptor tyrosine kinase (RTK)) will result in the initial protrusion required to set the directional compass and to define the direction of cell migration during chemotaxis ${ }^{56,78}$ and invasion ${ }^{57}$. 
Two types of protrusions have been implicated in chemotaxis of tumour cells: leading-edge protrusion $^{37,56}$ and invasive protrusions such as invadopodia and podosomes ${ }^{54,57}$. Invadopodia and podosomes form in response to chemotactic cytokines such as EGF and colony-stimulating factor 1 (CSF1; also known as MCSF) ${ }^{54,79}$. In two-dimensional cell culture, invadopodia and podosomes are found on the ventral surface of migrating tumour cells and macrophages, respectively, and are required for chemotaxis ${ }^{54,57}$. However, when these cells migrate in three-dimensional cultures, invadopodia and podosomes are found at the front of the cell, where they are associated with matrix degradation during locomotion 37,80 . Therefore, the dissection of mechanisms controlling cell protrusion, both at the leading edge and within invadopodia, is essential to understand chemotaxis and the subsequent invasion of tumour cells. The integration of the motility machinery in both of these protrusions with environmental cues that result in chemotaxis is currently under intense investigation.

\section{Molecular pathways of chemotaxis}

It is well established that the regulation of actin polymerization during tumour cell migration and invasion is controlled by RHO GTPases ${ }^{81}$. Initiation of chemotaxis occurs on binding of growth factors to GPCRs or RTKs, or adhesion of integrins to the ECM, which leads to changes in the localization or activation of guanine nucleotide exchange factors (GEFs) that in turn activate RHO GTPases ${ }^{81}$. During cell protrusion, actin polymerization within the leading-edge protrusion is under the control of the specific RHO GTPases RAC1, RAC2 and RHOA (and possibly RHOC), whereas actin polymerization within the invadopodium is under the control of $\mathrm{RHOC}^{82}$. Various steering mechanisms have been proposed and studies in tumour cells suggest that cofilin severs filamentous actin (F-actin) to initiate the molecular compass for directing actin polymerization within leading-edge protrusions and invadopodia. Directing actin polymerization to these specific locations promotes tumour cell motility and invasion during single cell migration ${ }^{56,78,79,83}$, and aids pathfinding cells during collective migration ${ }^{84}$.

During tumour cell chemotaxis, all pathways that control actin polymerization are spatially and temporally coordinated ${ }^{85}$. These include activation of cofilin and activation of the neural Wiskott-Aldrich syndrome protein (NWASP)-WASP family verprolin homologous protein (WAVE)-actin-related protein 2 (ARP2)-ARP3 pathway. In tumour cells, the cofilin-dependent actin polymerization that is required for leading-edge protrusion and invadopodium assembly is regulated by phospholipase $\mathrm{C} \gamma 1$ (PLC $\gamma 1)^{86}$ and RHOC $^{82}$ (FIG. 1a). Following initial cofilin-dependent protrusion, $\mathrm{RAC} 1$ leads to the formation of a WAVE2-insulin receptor substrate p53 (IRSP53; also known as BAIAP2)-ABL-interactor 1 (ABI1) complex, which activates the ARP2-ARP3 complex ${ }^{87}$. As a result, the ARP2-ARP3 complex nucleates actin filaments from the sides of cofilin-generated filaments in both lamellipodia and invadopodia ${ }^{83,88,89}$ (FIG. 1a). In addition, coordinated regulation between the WASP family and the formin mammalian diaphanous homologue 1 (MDIA1; also known as DIAPH1) shifts the balance of actin polymerization from the body to the tip of the leading-edge protrusion in tumour cells ${ }^{83}$. In the absence of RAC1- and RAC2-mediated lamellipodial protrusion, MDIA1 is activated by RHOA and promotes lamellar protrusions ${ }^{83}$. Cortactin (CTTN) regulation of cofilin and NWASP is important in the 
control of the stages of invadopodium assembly and maturation ${ }^{79,90,91}$. The intricate regulation of these mechanisms is essential for the proper control of the direction of protrusion and thus chemotaxis in tumour cells.

The LEGI model ${ }^{46}$ has been used successfully to describe the spatial regulation of cofilin as part of the cofilin activity cycle in different subcellular compartments within tumour cells ${ }^{79}$. This localized activity is responsible for the asymmetric actin polymerization observed within leading-edge protrusions and invadopodia. In the tumour cell LEGI model, local activation of cofilin and global inhibition of cofilin activity by LIM domain kinase 1 (LIMK1) focuses the cofilin-dependent actin polymerization activity in leading-edge protrusions and in invadopodia ${ }^{58,79,82}$ (FIG. 1b). Different starting points in a single common activity cycle control the mechanisms required for initiation of local excitation and global inhibition ${ }^{59}$. For example, in an unstimulated tumour cell, cofilin is bound to either phosphatidylinositol 4,5-bisphosphate $\left(\mathrm{PI}(4,5) \mathrm{P}_{2}\right)$ at the plasma membrane, or CTTN at the future site of the invadopodium. The cofilin activity cycle in tumour cells begins in lamellipodia with the local activation of cofilin by PLC $\gamma 1$-dependent hydrolysis of $\mathrm{PI}(4,5) \mathrm{P}_{2}$ and in invadopodia with the SRC-initiated Abelson-related gene (ARG; also known as ABL2) kinase-dependent tyrosine phosphorylation of CTTN ${ }^{79,86,89}$ (FIG. 1a). In an EGF-stimulated tumour cell, dephosphorylation of cofilin by RAC2 is necessary to sustain but not to initiate the cofilin activity cycle ${ }^{79,86}$. However, the initiation of neutrophil motility by $\mathrm{N}$-formylmethionyl-leucylphenylalanine (fMLP) involves the dephosphorylation of cofilin, thereby initiating the cofilin activity cycle at a different starting point from that seen in tumour cells (reviewed in REF. 59) (FIG. 1a).

\section{Steps of chemotaxis}

The LEGI model, in which a cell can reorient itself accurately in a chemotactic gradient, is one version of a 'chemotactic compass model'. In addition to tumour cells, compass models have been described for other cell types such as neutrophils ${ }^{55}$ and $D$. discoideum ${ }^{49}$. A compass model for chemotactic sensing is consistent with photo-activation experiments, in which activation of either cofilin ${ }^{78}$ or $\mathrm{RAC}^{92}$ at the cell edge is sufficient to induce local actin polymerization and new pseudopod extension, which defines a new cell front. Because both the cofilin and RAC pathways converge on ARP2-ARP3 complex-dependent actin polymerization (FIG. 1a), their activation seems to be sufficient to generate the local break in symmetry of actin polymerization that is required for a change in cell direction as defined by the protrusion.

Another model of chemosensing is the random protrusion model ${ }^{93}$, which proposes that pseudopods arise only from pre-existing pseudopods, thus defining a narrow range of physical locations where pseudopods can form. This model states that cells do not reorient themselves by generating protrusions up the gradient, and that actin polymerization in pseudopods is regulated intrinsically, independent from external chemotactic gradients. The applicability of this model to tumour cells is unclear for several reasons. First, if the position of the source of a gradient is moved from the cell front to the cell rear, tumour cells can convert the rear (with no pre-existing pseudopods) into a cell front with pseudopods ${ }^{94}$. According to the random protrusion model, the cell would have to make a U-turn while 
maintaining the same cell front, which is not observed. Second, migratory tumour cells from mammary tumours have elevated sensitivity to EGF such that pseudopods are directed precisely up an EGF gradient ${ }^{5,8}$. Finally, the location of actin polymerization in mammalian cells is defined by external signals that, by breaking symmetry in the actin cytoskeleton, can cause pseudopod extension up a gradient ${ }^{56}$ or towards photo-activated cofilin or RAC ${ }^{78,92}$. Further work will be required to investigate the relevance of the random protrusion model to the chemotaxis of tumour cells in particular.

The second step of chemotaxis, cell polarization, involves the development of stable cell polarity, with a front and back, where the cell front is positioned towards the source of chemoattractant. Myosin I has been implicated in the suppression of lateral pseudopod extension in $D$. discoideum to maintain cell polarity during locomotion in a chemotactic gradient ${ }^{95}$. In addition, in neutrophils and $D$. discoideum, evidence indicates that PI3K regulates the acquisition of stable cell polarity by defining actin filament stability and myosin II contractility $49,55,92$.

The third step in chemotaxis involves retraction of the rear of the cell (the 'tail') leading to cell locomotion. This step involves myosin II-mediated contraction at the tail ${ }^{50}$ and the polarized release of cell adhesions at the tail ${ }^{96}$. The synchronization of these three steps, chemosensing, polarization and tail retraction/locomotion, results in chemotaxis. Further work is required to determine how these steps are choreographed in tumour cells.

Many studies in tumour cells have identified specific adaptor proteins that associate with chemokine and growth factor receptors in order to tune the scale of the biological response to environmental cues. For example, the enabled (ENA)-vasodilator-stimulated phosphoprotein (VASP) family of proteins has been implicated in the control of cell motility during cancer progression ${ }^{97,98}$. In particular, an alternatively spliced isoform of mammalian

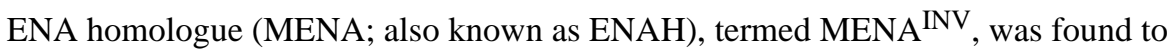
antagonize capping proteins (FIG. 1a) and to potentiate EGF-induced carcinoma cell invasion, chemotaxis and metastasis. This was shown to occur through sensitization of the EGF receptor (EGFR), allowing the tumour cell to respond to very low concentrations of $\mathrm{EGF}^{5,97}$ and to detect very shallow gradients ${ }^{8}$. Moreover, MENA ${ }^{\mathrm{INV}}$ was overexpressed specifically in the invasive tumour cells of rat, mouse and human primary breast tumours that were isolated in vivo by chemotaxis from tumours ${ }^{99}$. It is important to continue to identify modulators of regulatory processes involved in the chemotaxis of cancer cells to determine whether there are additional molecules that, like MENA ${ }^{\mathrm{INV}}$, serve as master regulators of this process, and thus can influence chemotaxis by sensitizing cells to detecting shallow gradients.

\section{Chemotaxis and the tumour microenvironment}

Chemotaxis not only affects tumour cells but also helps to shape the tumour microenvironment. Directional migration to a chemokine source is evident both in vitro and in vivo for most of the cells of the tumour microenvironment. Epithelial cells produce multiple factors that recruit various tumour-infiltrating cells, including tumour-associated macrophages (TAMs), tumour-associated neutrophils (TANs), lymphocytes, cancer- 
associated fibroblasts (CAFs), mesenchymal stem cells (MSCs) and endothelial cells (FIG. 2). These tumour-infiltrating cells also produce a series of chemokines and growth factors that lead to a complex network of communication within the tumour microenvironment (FIG. 2; TABLE 1). Several major events are affected by chemotaxis in the context of the tumour microenvironment: immune evasion, angiogenesis, invasion and dissemination.

\section{Immune evasion}

Immune evasion is one of the major effects of chemotaxis in the tumour microenvironment. A complex network of chemokines and other factors that are secreted by tumour cells, but also by other stromal cells, can lead to tolerogenic responses. Regulatory $\mathrm{T}\left(\mathrm{T}_{\mathrm{Reg}}\right)$ cells mediate immune tolerance by suppressing autoreactive $\mathrm{T}$ cells. $\mathrm{T}_{\text {Reg }}$ cells express the chemokine receptor CCR4 and can be attracted to ovarian cancer cells by the tumour celland macrophage-derived chemokine ligand CCL22 (REF. 100) (FIG. 2a). Additionally, CCL2 and CCL5 are major attractants of monocyte precursor cells in tumours and, when accumulated, these cells play an important part in tumour non-responsiveness by suppressing antigen-specific $\mathrm{T}$ cell responses ${ }^{101}$. Inside the tumour and under the influence of tumour-derived chemokines, both macrophages and neutrophils can polarize away from a tumour-suppressing phenotype (M1 and N1, respectively) towards a more tumourpromoting phenotype (M2 or N2, respectively $)^{102,103}$. Tumour-promoting macrophages and neutrophils then release immunosuppressive cytokines, such as interleukin-10 (IL-10), transforming growth factor- $\beta$ (TGF $\beta$ ) and various other chemokines such as CCL2, CCL4, CCL17, CCL22 and CXCL12. These chemokines, as well as producing large amounts of arginase, serve to inactivate $\mathrm{T}$ cell effector functions and contribute further towards a $\mathrm{T}$ helper $2\left(\mathrm{~T}_{\mathrm{H}} 2\right)$-polarized immunity ${ }^{71,102,104}$. In patients, the presence of both TAMs and TANs has been correlated with poor prognosis in many cancer types ${ }^{102,105,106}$. In addition, myeloid-derived suppressor cells (MDSCs), a heterogeneous collection of immature myeloid cells that may share common progenitors with macrophages, also migrate into tumours in response to the pro-inflammatory S100 calcium binding proteins and prostaglandin E2 (REFS 107-109). MDSCs suppress the adaptive immune response by further blocking the functions of $\mathrm{CD} 4^{+}$and $\mathrm{CD} 8^{+} \mathrm{T}$ cells. Finally, dendritic cells are recruited by CCL5, CXCL12 and CCL19 to the tumour, where they suppress tumourspecific immune responses ${ }^{110}$. In conclusion, a complex network of deregulated chemokines and other factors that are produced by tumour cells drive chemotaxis of immune cells into the tumour and subsequently manipulate the immune microenvironment from its normal tumour-suppressing functions to an abnormal dissemination-promoting function.

\section{Angiogenesis}

Angiogenesis not only facilitates tumour growth by supplying nutrients and oxygen to the tumour but is also a prerequisite for tumour cell dissemination and metastasis. Blood vessel density is correlated with a higher incidence of metastasis and a more rapid recurrence of disease ${ }^{111}$. Angiogenesis is the process whereby microvascular endothelial cells proliferate and sprout from pre-existing microvasculature towards the tumour. Directional migration of endothelial cells is a key process for their mobilization towards tumour cells, for which many chemoattractants have been characterized. 
First, tumour cells produce chemokines that act directly on endothelial cells. Endothelial cells express the chemokine receptors CXCR2, CXCR3, CXCR4 and CXCR7 and multiple ligands to these receptors are produced by tumour cells and can induce endothelial cell chemotaxis $^{74}$ (FIG. 2b). For example, the angiogenic potential of CCL11, a ligand for CXCR3, has been shown by various assays, including by standard chemotaxis assays in which migration of human microvascular endothelial cells was induced in vitro and in which vascularization was induced in vivo ${ }^{112}$. Additionally, CXCL1, CXCL2 and CXCL8 (also known as IL-8) have also been shown to have important roles in angiogenesis ${ }^{113}$, acting mainly by promoting chemotaxis of the CXCR2-expressing endothelial cells. In addition, CXCL12 is important in triggering endothelial cell migration and proliferation by binding to CXCR4 on the endothelial cell surface and can act synergistically with vascular endothelial growth factor (VEGF) to enhance the number of newly formed vessels ${ }^{114}$. CXCL12 can further act as a pro-angiogenic factor by recruiting CXCR4-expressing bone marrow-derived endothelial precursor cells (EPCs) to the tumour site, where they can differentiate into tumour-associated vascular endothelial cells and can actively incorporate into the newly formed vessels ${ }^{115}$. In addition, bone marrow-derived EPCs express CCR2 and CCR5 and therefore can also be attracted to the tumour site by the CCL2-, CCL3- and CCL5-producing tumour-associated endothelial cells ${ }^{74}$.

Furthermore, tumour cells can secrete chemoattractants that can indirectly affect tumour angiogenesis by regulating the immune infiltrate of the tumour (FIG. 2b). Myeloid monocytic cells such as TAMs, MDSCs and dendritic cells are recruited to the tumour site mainly by CCL2, and can produce many angiogenic factors such as VEGF, platelet-derived growth factor (PDGF), TGF $\beta$ and CXCL8 (REFS 108,110). MDSCs and monocytes might also directly promote angiogenesis by acquiring characteristics of endothelial cells and participating in the formation of new vessel architecture ${ }^{116}$. Finally, CXCL8 plays a part in angiogenesis through the recruitment of neutrophils ${ }^{105}$, which drive VEGF activation through MMP9 secretion ${ }^{117}$. Overall, chemotaxis is a crucial process for angiogenesis in tumours, either directly by attracting endothelial cells to sprout and form new vessels towards tumour cells or indirectly by manipulating the immune infiltrate to assume this angiogenesis-promoting role.

\section{Invasion and dissemination}

Both invasion within the primary tumour and dissemination to distant sites require chemotaxis. The most common chemokine receptor detected on cancer cells is CXCR4, with 23 different types of cancers showing expression of this receptor on the tumour cells ${ }^{74}$. CCR7 is another chemokine receptor frequently expressed in tumour cells. In standard chemotaxis assays in vitro, CXCR4-positive cancer cells can migrate in a directional manner towards CXCL12, whereas CCR7-expressing cancer cells can migrate towards CCL21 (FIG. 2c). Activating these receptors in breast cancer cells mediates actin polymerization and leading-edge protrusion, which contributes to a chemotactic and invasive response ${ }^{73}$. In the tumour microenvironment, CAFs that have either a fibroblastic or MSC origin ${ }^{118}$ can be a source of CXCL12 and can thus promote the directional migration of tumour cells towards blood vessels or the invasive edge of the tumour ${ }^{115}$. CAFs can also produce substantial 
levels of CXCL1, CXCL2, CXCL3 and CXCL8, which can act as chemoattractants for various tumour cells ${ }^{74}$.

Early work suggested that chemokine gradients could explain the tissue tropism observed in the metastasis of certain types of cancer. This model suggests that organs with high expression levels of specific chemokines can guide tumour cells expressing the corresponding receptor to that site as a result of locally induced chemotaxis and invasion ${ }^{73,74}$. This has been shown for the binding pairs CXCR4-CXCL12 in bone metastasis of breast and prostate tumours, CCL21-CCR7 and CCL19-CCR7 in lymph node metastasis of various solid and haematopoietic tumours and CCL27-CCR10 in skin metastasis of melanoma ${ }^{74,119,120}$. Another potential explanation could be that the arrival of tumour cells in a specific organ is passive, at least for haematogenous metastases, and that the site of dissemination simply reflects the first pass of the cells in the circulation and their entrapment in local capillaries ${ }^{121}$. In this model, chemokine receptor expression can give tissue specificity not in terms of active recruitment to a specific metastatic site but in terms of the receptor-expressing cells having an advantage to survive and grow in the new ligandrich metastatic microenvironment, because many of these chemotactic factors serve dual roles as cell growth and survival signals (discussed further in REF. 108).

In addition to CAFs, interactions with other cells within the tumour stroma can have a major influence on the migration behaviour of tumour cells in vivo. TAMs have been implicated in tumour cell invasion and metastasis in experimental models of breast cancer ${ }^{122}$. In polyoma middle $\mathrm{T}$ antigen (PyMT) transgenic mouse mammary tumours, TAMs comigrate with tumour cells in a paracrine loop-dependent manner in which EGF that is produced by TAMs increases the migration of EGFR-expressing breast cancer cells. In response, cancer cells secrete CSF1, which attracts CSF1 receptor (CSF1R)-expressing TAMs ${ }^{123}$ (FIG. 2c). In patients with breast cancer, $>50 \%$ of breast tumours have concomitant expression of CSF1 and CSF1R by tumour cells ${ }^{124}$, raising the potential for autocrine signalling. Indeed, in mammary tumours derived from MDA-MB-231 cells, TGF $\beta$-dependent expression of CSF1R in the tumour cells in vivo supports both paracrine interactions with TAMs and autocrine CSF1-CSF1R signalling. Both pathways are essential for in vivo relay chemotaxis, migration and invasion of these tumour cells ${ }^{125}$. In addition to EGF and CSF1, other chemoattractants in the tumour microenvironment, such as CXCL12 and heregulin (also known as NRG1), trigger chemotaxis of tumour cells in transgenic and xenograft models of breast cancer ${ }^{126}$. Interestingly, migration to both CXCL12 and heregulin requires macrophages and the EGF-CSF1 paracrine interaction with tumour cells, suggesting that this tumour cell-macrophage interaction is a 'central engine' that drives the invasion and migration of breast cancer cells ${ }^{126}$. CXCL12 can also be produced by pericytes and tumour cells, suggesting that a very complex network of chemotactic gradients from multiple cell types governs directional migration and invasion of tumour cells (FIG. 2c).

Intravasation is a major route of tumour cell dissemination from solid tumours. Intravasation has been directly observed using multiphoton imaging and fate mapping of breast tumours $5,20,127,128$ (FIG. 3). In breast tumours, high-resolution multiphoton imaging in vivo has shown that migration and intravasation are both dependent on the EGF-CSF1 macrophage-tumour cell paracrine loop ${ }^{123,127}$, which leads to relay chemotaxis and in turn 
leads to multicellular streaming migration towards blood vessels and subsequent intravasation 5,19,20,123,127 (FIG. 3). Another model has been proposed for the CCR7dependent chemotaxis of tumour cells towards lymphatics ${ }^{60}$. The autologous model for chemotaxis assumes a continuous fluid flow from blood vessels to lymphatics to establish a gradient of chemoattractant towards lymphatics. This would cause tumour cell chemotaxis towards lymphatics and away from blood vessels. The extent to which this phenomenon occurs in different tumour types in live tissues has not been studied. Although this model could help to explain lymphatic dissemination, it cannot explain the commonly observed active migration of breast tumour cells towards blood vessels.

In vivo studies of chemotaxis have shown that tumour cells can respond to shallow gradients generated from various devices designed to deliver known amounts of EGF and other chemoattractants $5,8,123,125,126$. In these experiments, tumour cells respond to a <2\% EGF gradient across the cell diameter, demonstrating their ability to chemotax in extremely shallow concentration gradients. This is particularly interesting in the context of tumour cell invasion and dissemination in vivo, because migratory breast tumour cells express a unique MENA isoform profile: MENA ${ }^{\mathrm{INV}}$ upregulated and MENA11A downregulated ${ }^{99}$, which dramatically increases the sensitivity of EGFR to EGF by $25-50$-fold ${ }^{5,97}$. Furthermore, MENA $^{\mathrm{INV}}$ is essential for transendothelial migration during intravasation ${ }^{5,129}$. All of these effects seem to result from the ability of MENA ${ }^{\text {INV }}$ to sensitize tumour cells to EGF, which amplifies the paracrine interaction with macrophages and results in increased multicellular streaming migration and intravasation in vivo ${ }^{5}$ (FIG. 3). Importantly, Robinson et al. ${ }^{130}$ have recently reported that microanatomical structures, which resemble the sites of intravasation observed in mouse mammary tumours by intravital multiphoton imaging, are found in paraffin-embedded tumour tissue from breast cancer patients. These structures, called tumour microenvironment of metastasis (TMEM), contain invasive tumour cells marked by MENA overexpression and perivascular macrophages that are in direct contact with endothelial cells, as observed at sites of intravasation in mouse mammary tumours ${ }^{127}$ (FIG. 4). The presence of TMEM is significantly correlated with the development of distant organ metastasis in patients with breast cancer ${ }^{130}$. Recently, it was shown that the presence of TMEM is strongly correlated with MENA ${ }^{\mathrm{INV}}$ expression in non-cohesive human breast tumour cells obtained by fine needle aspiration from breast tumours ${ }^{131}$, supporting the hypothesis that tumour cell-macrophage streams that form in response to MENA ${ }^{\mathrm{INV}}$ are involved in TMEM assembly. These findings highlight the clinical relevance of paracrine chemotaxis in tumour cell dissemination.

\section{Conclusions and perspectives}

Given the importance of chemotaxis in cancer, the development of therapeutics targeting chemotaxis is an obvious goal for the cancer research community. The recent development of autonomous chemotaxis devices that can be implanted in tumours to evaluate chemotactic events in vivo will help to define more precisely the importance of specific chemotactic signals in tumour cell migration ${ }^{8}$. In addition, various compounds are being developed to target many of the factors discussed above and some of them are already in use, whereas others are in clinical trials (Supplementary information S1 (table)). For example, multiple compounds have been developed for the ERBB family of receptors, either as monoclonal 
antibodies against extracellular domains or as specific tyrosine kinase inhibitors (TKIs) targeting intracellular signalling. As far as chemokines and their receptors are concerned, several therapeutics are currently under investigation in multiple clinical trials. Most of these compounds target CXCR4 as it was one of the first chemokine receptors found to be overexpressed in many types of cancer ${ }^{74,132}$. In addition to receptors and their ligands, compounds targeting downstream effectors of these chemotactic pathways, such as mTOR, PI3K, SRC, MET and MEK, are currently undergoing preclinical and clinical Phase I/II evaluation ${ }^{133}$. Expression profiling of invasive and metastatic cells from mouse models has identified additional factors that regulate chemotaxis in tumour cells and thus could serve as potential novel therapeutic targets ${ }^{134-137}$.

The first effort to develop therapeutics specifically targeting the tumour microenvironment resulted in anti-angiogenesis therapy. Several VEGF antagonists are now approved by the US Food and Drug Administration ${ }^{138}$ and have been shown to increase the survival of patients with metastatic breast and colorectal cancers when combined with standard chemotherapy ${ }^{139,140}$ (Supplementary information S1 (table)). In addition to targeting VEGF, several compounds targeting chemokines are expected to not only inhibit the migration of tumour cells but also to abolish angiogenesis. For example, CXCR4 is expressed on tumour cells and endothelial cells, and compounds that target this receptor could both inhibit tumour cell migration and angiogenesis. In addition, humanized anti-CXCL8 antibodies inhibited angiogenesis, tumour growth and metastasis in melanoma and bladder cancer xenografts ${ }^{141,142}$. Neutralization of CCL2 also resulted in reduced metastasis, mainly due to decreased angiogenesis, in breast cancer xenografts ${ }^{112}$.

Despite the strong experimental evidence for the involvement of the signalling pathways discussed above in chemotaxis and tumour cell dissemination, the therapeutics actively being developed are engineered primarily with growth and proliferation in mind, and thus they are being tested for their ability to reduce the size and growth of primary and/or secondary tumours. This seems problematic because dissemination and growth are not always linked, and therefore useful information regarding any potential benefit of these drugs in preventing dissemination is missed. One reason that chemotaxis and dissemination are not being directly tested is the lack of relevant therapeutic end points in current clinical practice. We speculate that the new insights coming from research on chemotaxis and dissemination will lead to novel end point markers for the evaluation of therapeutics designed to inhibit the pathways of chemotaxis and dissemination. For example, measuring chemotaxis by novel diagnostic devices in patients, counting circulating tumour cells (CTCs) and counting TMEM occurrences are potential end point markers for chemotaxisand dissemination-directed therapy. In addition, anti-invasion and anti-dissemination therapy may require chronic prophylactic treatment of patients after the initial treatment of the primary tumour. In this scenario, the potential drug will have to be well tolerated for use over many years in order to prevent further dissemination from secondary tumour sites. Even in this setting, treatment will probably have to be combined with therapies that target the growth potential of already disseminated minimal residual disease.

It has been argued that because dissemination from the primary tumour can occur early in cancer progression, potentially before clinical presentation ${ }^{143}$, anti-invasion and anti- 
dissemination therapy may not be a plausible target for cancer therapy, but instead that future therapeutics should target the growth of dormant, already disseminated cells ${ }^{144}$. However, invasion and dissemination can still be clinically relevant targets after resection of the primary tumour, because tumour cells can disseminate from metastatic sites and seed back to the primary tumour site or other metastatic sites ${ }^{145}$. CTCs can be found in the blood of patients years or decades after the removal of their primary tumour ${ }^{146}$, suggesting that secondary deposits of tumour cells in the body of the patient can still regularly invade and disseminate into the blood circulation. Additionally, the number of CTCs in the peripheral blood of patients is prognostic for cancer recurrence and poor survival (for example, REFS 147-149), suggesting that these cells are causative for further metastasis. In our opinion, and that of others (for example, REFS 150,151), anti-invasion and anti-dissemination therapy can be combined with other therapies to more effectively manage cancer dissemination and subsequent growth. Such treatments will hopefully lead to efficient long-term management of minimal residual disease without relapse or complicating metastases.

\section{Supplementary Material}

Refer to Web version on PubMed Central for supplementary material.

\section{Acknowledgments}

The authors would like to thank members of the Condeelis laboratory for helpful discussions. We thank especially J. Wyckoff and D. Entenberg, associates at the Gruss Lipper Biophotonics Center (GLBC) of the Albert Einstein College of Medicine, for their critical comments and suggestions for this manuscript and their help in figure preparation. The authors apologize to those whose work is not cited owing to space limitations. The authors' research is funded by grants CA150344 (to E.T.R), CA100324 (to J.S.C.) and CA113395 (to A.P.) from the US National Institutes of Health.

\section{Glossary}

Chemotaxis

Intravasation

Extravasation

Chemokines

Growth factors

Haptotaxis

Electrotaxis
Polarized migration in response to soluble extracellular cues

The process by which a cell invades through the basement membrane and the endothelium to enter blood vessels

The process by which a cell exits a blood vessel or capillary to enter a tissue

A family of inducible chemoattractant cytokines that regulate the chemotaxis of tumour cells and other cell types. Chemokines also affect processes such as proliferation, migration and invasion

Can be considered chemokines that specifically but not exclusively affect cell proliferation

Migration in response to a solid state, extracellular cue. These cues include graded adhesion within the substrate or anchored chemotactic factors within the extracellular matrix

Migration in response to changes in electric fields 


\section{Durotaxis \\ Cytokines \\ Chemosensing \\ Polarization}

Locomotion

Amoeboid

migration

\section{Mesenchymal migration}

\section{Collective \\ migration}

Cell streaming

\section{Leading-edge protrusion}

\section{Invadopodia}

Migration in response to mechanical signals within the microenvironment

Small, secreted proteins produced by immune cells that are used in cellular communication

The process by which a cell senses the direction of a gradient source

The process by which a cell becomes polarized towards a sensed gradient source

Migration towards a gradient source, which involves retraction of the back of the cell

Leading-edge protrusion of a rounded or ellipsoid cell, usually characterized by many protrusions, which result in a high turning frequency. The formation of a dominant protrusion is followed by the retraction of the trailing edge and the inhibition of randomly directed lateral pseudopod extensions

The formation of a single or few actin-rich leading-edge protrusions, usually characterized by a low turning frequency, giving rise to a more polarized cell. Leading-edge protrusion is followed by adhesive interactions of the leading edge with the extracellular matrix, which triggers the contraction of the rear of the cell and finally cell displacement

The movement of groups of cells with functionally intact cell-cell adhesions that coordinate multicellular leading-edge protrusions and trailing-edge retraction. This type of cell movement usually occurs at very low velocities $\left(\sim 0.1 \mu \mathrm{m} \mathrm{min}^{-1}\right)$

The movement of a group of individual carcinoma cells, the vector paths of which point in the same direction. Cell movement is usually coordinated by chemotaxis, whereby the cells align and move in single file but do not require intact junctions or even contact between carcinoma cells. Streaming cells have velocities of migration 10-100 times more rapid than cells undergoing collective migration

A protrusion at the leading edge of a cell. The term includes all locomotory protrusions, such as lamellipodia and pseudopodia, that are used by chemotaxing cells

Actin-based membrane protrusions with matrix metalloproteinase activity that degrades the extracellular matrix. Shapes of invadopodia vary and can involve either a large area of the leading-edge protrusion when cells are in three-dimensional culture conditions, or small dots on the ventral surface of the cell when cultured in twodimensional conditions 


\section{Tolerogenic response}

T helper 2

Tissue tropism

Relay

chemotaxis
An acquired specific failure of the immune system to respond to a given antigen. In the case of cancer, the tumour cells secrete factors that manipulate the immune system into inhibiting cytotoxic activities

$\left(\mathrm{T}_{\mathrm{H}} 2\right)$. T cells that help $\mathrm{B}$ cells to make antibodies and suppress the action of cytotoxic $T$ cells. By contrast, $T$ helper $1\left(\mathrm{~T}_{\mathrm{H}} 1\right)$ cells are at the other end of the functional spectrum and activate macrophages and cytotoxic $\mathrm{T}$ cells

An affinity of cells or microorganisms for specific host tissues. In cancer it refers to the selectivity of metastasis formation in specific organs

The asymmetric propagation of a chemotactic signal, resulting in collective and streaming migration

\section{References}

1. Condeelis J, Singer RH, Segall JE. The great escape: when cancer cells hijack the genes for chemotaxis and motility. Annu Rev Cell Dev Biol. 2005; 21:695-718. [PubMed: 16212512]

2. McSherry EA, Donatello S, Hopkins AM, McDonnell S. Molecular basis of invasion in breast cancer. Cell Mol Life Sci. 2007; 64:3201-3218. [PubMed: 17957337]

3. Farrow B, Albo D, Berger DH. The role of the tumor microenvironment in the progression of pancreatic cancer. J Surg Res. 2008; 149:319-328. [PubMed: 18639248]

4. Condeelis J, Segall JE. Intravital imaging of cell movement in tumours. Nature Rev Cancer. 2003; 3:921-930. [PubMed: 14737122]

5. Roussos ET, et al. Mena invasive (Mena ${ }^{\mathrm{INV}}$ ) promotes multicellular streaming motility and transendothelial migration in a mouse model of breast cancer. J Cell Sci. 2011; 124:2120-2131. This study demonstrates how a MENA invasion-specific isoform promotes multicellular streaming in vivo in mouse models of breast cancer. This was the first study to define multicellular streaming migration of breast tumour cells in vivo by intravital imaging. [PubMed: 21670198]

6. Petrie RJ, Doyle AD, Yamada KM. Random versus directionally persistent cell migration. Nature Rev Mol Cell Biol. 2009; 10:538-549. [PubMed: 19603038]

7. Provenzano PP, Eliceiri KW, Inman DR, Keely PJ. Engineering three-dimensional collagen matrices to provide contact guidance during 3D cell migration. Curr Protoc Cell Biol. 2010; 47:10.17.1-10.17.11.

8. Raja WK, Gligorijevic B, Wyckoff J, Condeelis JS, Castracane J. A new chemotaxis device for cell migration studies. Integr Biol. 2010; 2:696-706.

9. Berthier E, Surfus J, Verbsky J, Huttenlocher A, Beebe D. An arrayed high-content chemotaxis assay for patient diagnosis. Integr Biol. 2010; 2:630-638.

10. Skoge M, et al. Gradient sensing in defined chemotactic fields. Integr Biol. 2010; 2:659-668.

11. Bosgraaf L, Keizer-Gunnink I, Van Haastert PJ. PI3-kinase signaling contributes to orientation in shallow gradients and enhances speed in steep chemoattractant gradients. J Cell Sci. 2008; 121:3589-3597. [PubMed: 18840645]

12. Patel DD, et al. Chemokines have diverse abilities to form solid phase gradients. Clin Immunol. 2001; 99:43-52. [PubMed: 11286540]

13. Iglesias PA, Devreotes PN. Navigating through models of chemotaxis. Curr Opin Cell Biol. 2008; 20:35-40. [PubMed: 18207721]

14. Friedl P, Wolf K. Plasticity of cell migration: a multiscale tuning model. J Cell Biol. 2010; 188:11-19. [PubMed: 19951899] 
15. Sahai E. Mechanisms of cancer cell invasion. Curr Opin Genet Dev. 2005; 15:87-96. [PubMed: 15661538]

16. Smalley KS, Lioni M, Herlyn M. Life isn't flat: taking cancer biology to the next dimension. In Vitro Cell Dev Biol Anim. 2006; 42:242-247. [PubMed: 17163781]

17. Gaggioli C, et al. Fibroblast-led collective invasion of carcinoma cells with differing roles for RhoGTPases in leading and following cells. Nature Cell Biol. 2007; 9:1392-1400. This study demonstrates that fibroblasts lead the collective migration of SCC cells through the generation of tracks in the ECM by degradation or matrix remodelling. [PubMed: 18037882]

18. Rhee $\mathrm{S}$. Fibroblasts in three dimensional matrices: cell migration and matrix remodeling. Exp Mol Med. 2009; 41:858-865. [PubMed: 19745603]

19. Goswami S, et al. Macrophages promote the invasion of breast carcinoma cells via a colonystimulating factor-1/epidermal growth factor paracrine loop. Cancer Res. 2005; 65:5278-5283. [PubMed: 15958574]

20. Kedrin D, et al. Intravital imaging of metastatic behavior through a mammary imaging window. Nature Methods. 2008; 5:1019-1021. [PubMed: 18997781]

21. Pinner S, Sahai E. Imaging amoeboid cancer cell motility in vivo. J Microsc. 2008; 231:441-445. [PubMed: 18754999]

22. Friedl P, Gilmour D. Collective cell migration in morphogenesis, regeneration and cancer. Nature Rev Mol Cell Biol. 2009; 10:445-457. [PubMed: 19546857]

23. Wolf $\mathrm{K}$, et al. Compensation mechanism in tumor cell migration: mesenchymal-amoeboid transition after blocking of pericellular proteolysis. J Cell Biol. 2003; 160:267-277. A key paper demonstrating that tumour cells can transition between the two types of single cell migration, amoeboid and mesenchymal, through inhibition of pericellular proteolysis. [PubMed: 12527751]

24. Wyckoff JB, Pinner SE, Gschmeissner S, Condeelis JS, Sahai E. ROCK- and myosin-dependent matrix deformation enables protease-independent tumor-cell invasion in vivo. Curr Biol. 2006; 16:1515-1523. [PubMed: 16890527]

25. Thiery JP, Acloque H, Huang RY, Nieto MA. Epithelial-mesenchymal transitions in development and disease. Cell. 2009; 139:871-890. [PubMed: 19945376]

26. Nabeshima K, Inoue T, Shimao Y, Sameshima T. Matrix metalloproteinases in tumor invasion: role for cell migration. Pathol Int. 2002; 52:255-264. [PubMed: 12031080]

27. Sahai E, Marshall CJ. Differing modes of tumour cell invasion have distinct requirements for Rho/ ROCK signalling and extracellular proteolysis. Nature Cell Biol. 2003; 5:711-719. [PubMed: 12844144]

28. Pankova K, Rosel D, Novotny M, Brabek J. The molecular mechanisms of transition between mesenchymal and amoeboid invasiveness in tumor cells. Cell Mol Life Sci. 2009; 67:63-71. [PubMed: 19707854]

29. Valentin G, Haas P, Gilmour D. The chemokine SDF1a coordinates tissue migration through the spatially restricted activation of Cxcr7 and Cxcr4b. Curr Biol. 2007; 17:1026-1031. [PubMed: 17570670]

30. Schmidt M, et al. EGFL7 regulates the collective migration of endothelial cells by restricting their spatial distribution. Development. 2007; 134:2913-2923. [PubMed: 17626061]

31. Lecaudey V, Cakan-Akdogan G, Norton WH, Gilmour D. Dynamic Fgf signaling couples morphogenesis and migration in the zebrafish lateral line primordium. Development. 2008; 135:2695-2705. [PubMed: 18599504]

32. Haas P, Gilmour D. Chemokine signaling mediates self-organizing tissue migration in the zebrafish lateral line. Dev Cell. 2006; 10:673-680. [PubMed: 16678780]

33. Aman A, Piotrowski T. Wnt/ $\beta$-catenin and Fgf signaling control collective cell migration by restricting chemokine receptor expression. Dev Cell. 2008; 15:749-761. [PubMed: 19000839]

34. Rorth P. Collective guidance of collective cell migration. Trends Cell Biol. 2007; 17:575-579. [PubMed: 17996447]

35. Ilina O, Friedl P. Mechanisms of collective cell migration at a glance. J Cell Sci. 2009; 122:32033208. [PubMed: 19726629]

36. Wolf K, et al. Multi-step pericellular proteolysis controls the transition from individual to collective cancer cell invasion. Nature Cell Biol. 2007; 9:893-904. [PubMed: 17618273] 
37. Packard BZ, Artym VV, Komoriya A, Yamada KM. Direct visualization of protease activity on cells migrating in three-dimensions. Matrix Biol. 2009; 28:3-10. [PubMed: 19010413]

38. Clark ES, Whigham AS, Yarbrough WG, Weaver AM. Cortactin is an essential regulator of matrix metalloproteinase secretion and extracellular matrix degradation in invadopodia. Cancer Res. 2007; 67:4227-4235. [PubMed: 17483334]

39. Nabeshima K, et al. Front-cell-specific expression of membrane-type 1 matrix metalloproteinase and gelatinase A during cohort migration of colon carcinoma cells induced by hepatocyte growth factor/scatter factor. Cancer Res. 2000; 60:3364-3369. [PubMed: 10910039]

40. Friedl P, Wolf K. Tube travel: the role of proteases in individual and collective cancer cell invasion. Cancer Res. 2008; 68:7247-7249. [PubMed: 18794108]

41. Farooqui R, Fenteany G. Multiple rows of cells behind an epithelial wound edge extend cryptic lamellipodia to collectively drive cell-sheet movement. J Cell Sci. 2005; 118:51-63. [PubMed: 15585576]

42. Giampieri S, et al. Localized and reversible TGF $\beta$ signalling switches breast cancer cells from cohesive to single cell motility. Nature Cell Biol. 2009; 11:1287-1296. This study is the first to show active TGF $\beta$ signalling in cells undergoing single cell migration in vivo. Importantly, in distant metastasis TGF $\beta$ signalling was found to be inactivated, suggesting that microenvironmental chemotaxis signals in primary tumours are transient. [PubMed: 19838175]

43. Kriebel PW, Barr VA, Parent CA. Adenylyl cyclase localization regulates streaming during chemotaxis. Cell. 2003; 112:549-560. [PubMed: 12600317]

44. Kriebel PW, Barr VA, Rericha EC, Zhang G, Parent CA. Collective cell migration requires vesicular trafficking for chemoattractant delivery at the trailing edge. J Cell Biol. 2008; 183:949961. [PubMed: 19047467]

45. Li S, Guan JL, Chien S. Biochemistry and biomechanics of cell motility. Annu Rev Biomed Eng. 2005; 7:105-150. [PubMed: 16004568]

46. Devreotes P, Janetopoulos C. Eukaryotic chemotaxis: distinctions between directional sensing and polarization. J Biol Chem. 2003; 278:20445-20448. [PubMed: 12672811]

47. Veltman DM, Keizer-Gunnik I, Van Haastert PJ. Four key signaling pathways mediating chemotaxis in Dictyostelium discoideum. J Cell Biol. 2008; 180:747-753. [PubMed: 18299345]

48. Annesley SJ, Fisher PR. Dictyostelium discoideum - a model for many reasons. Mol Cell Biochem. 2009; 329:73-91. References 47 and 48 are comprehensive reviews of how $D$. discoideum serves as a model for the study of chemotaxis signalling. [PubMed: 19387798]

49. Swaney KF, Huang CH, Devreotes PN. Eukaryotic chemotaxis: a network of signaling pathways controls motility, directional sensing, and polarity. Annu Rev Biophys. 2010; 39:265-289. [PubMed: 20192768]

50. Chung CY, Funamoto S, Firtel RA. Signaling pathways controlling cell polarity and chemotaxis. Trends Biochem Sci. 2001; 26:557-566. [PubMed: 11551793]

51. Janetopoulos C, Firtel RA. Directional sensing during chemotaxis. FEBS Lett. 2008; 582:20752085. [PubMed: 18452713]

52. King JS, Insall RH. Chemotaxis: finding the way forward with Dictyostelium. Trends Cell Biol. 2009; 19:523-530. [PubMed: 19733079]

53. Jin T, et al. How human leukocytes track down and destroy pathogens: lessons learned from the model organism Dictyostelium discoideum. Immunol Res. 2009; 43:118-127. [PubMed: 18827980]

54. Zicha D, et al. Chemotaxis of macrophages is abolished in the Wiskott-Aldrich syndrome. Br J Haematol. 1998; 101:659-665. [PubMed: 9674738]

55. Weiner OD. Regulation of cell polarity during eukaryotic chemotaxis: the chemotactic compass. Curr Opin Cell Biol. 2002; 14:196-202. A comprehensive review of the signalling components that regulate chemosensing and polarization. [PubMed: 11891119]

56. Mouneimne G, et al. Spatial and temporal control of cofilin activity is required for directional sensing during chemotaxis. Curr Biol. 2006; 16:2193-2205. This study demonstrates that local activation of cofilin by PLC and its global inactivation by LIMK1 phosphorylation combine to generate a local asymmetry of actin polymerization that is required for chemotaxis. [PubMed: 17113383] 
57. Desmarais V, et al. N-WASP and cortactin are involved in invadopodium-dependent chemotaxis to EGF in breast tumor cells. Cell Motil Cytoskeleton. 2009; 66:303-316. [PubMed: 19373774]

58. Wang W, Eddy R, Condeelis J. The cofilin pathway in breast cancer invasion and metastasis. Nature Rev Cancer. 2007; 7:429-440. [PubMed: 17522712]

59. van Rheenen J, Condeelis J, Glogauer M. A common cofilin activity cycle in invasive tumor cells and inflammatory cells. J Cell Sci. 2009; 122:305-311. [PubMed: 19158339]

60. Shields JD, et al. Autologous chemotaxis as a mechanism of tumor cell homing to lymphatics via interstitial flow and autocrine CCR7 signaling. Cancer Cell. 2007; 11:526-538. [PubMed: 17560334]

61. Ramjeesingh R, Leung R, Siu CH. Interleukin-8 secreted by endothelial cells induces chemotaxis of melanoma cells through the chemokine receptor CXCR1. FASEB J. 2003; 17:1292-1294. [PubMed: 12738812]

62. Reiland J, Furcht LT, McCarthy JB. CXC-chemokines stimulate invasion and chemotaxis in prostate carcinoma cells through the CXCR2 receptor. Prostate. 1999; 41:78-88. [PubMed: 10477904]

63. Liu Y, et al. Down-regulation of PKCzeta expression inhibits chemotaxis signal transduction in human lung cancer cells. Lung Cancer. 2009; 63:210-218. [PubMed: 18701187]

64. Liu Z, Klominek J. Chemotaxis and chemokinesis of malignant mesothelioma cells to multiple growth factors. Anticancer Res. 2004; 24:1625-1630. [PubMed: 15274332]

65. Tong GM, Rajah TT, Zang XP, Pento JT. The effect of antiestrogens on TGF- $\beta$-mediated chemotaxis of human breast cancer cells. Anticancer Res. 2002; 22:103-106. [PubMed: 12017270]

66. Hayashibara T, et al. Vascular endothelial growth factor and cellular chemotaxis: a possible autocrine pathway in adult T-cell leukemia cell invasion. Clin Cancer Res. 2001; 7:2719-2726. [PubMed: 11555584]

67. Bailly M, et al. Epidermal growth factor receptor distribution during chemotactic responses. Mol Biol Cell. 2000; 11:3873-3883. [PubMed: 11071913]

68. Hurst JH, Hooks SB. Regulator of G-protein signaling (RGS) proteins in cancer biology. Biochem Pharmacol. 2009; 78:1289-1297. [PubMed: 19559677]

69. Insall RH, Machesky LM. Actin dynamics at the leading edge: from simple machinery to complex networks. Dev Cell. 2009; 17:310-322. [PubMed: 19758556]

70. Hoeller O, Kay RR. Chemotaxis in the absence of PIP3 gradients. Curr Biol. 2007; 17:813-817. [PubMed: 17462897]

71. Balkwill F. Cancer and the chemokine network. Nature Rev Cancer. 2004; 4:540-550. [PubMed: 15229479]

72. Murphy PM. Chemokines and the molecular basis of cancer metastasis. N Engl J Med. 2001; 345:833-835. [PubMed: 11556308]

73. Muller A, et al. Involvement of chemokine receptors in breast cancer metastasis. Nature. 2001; 410:50-56. A seminal paper that demonstrates the role of chemokine receptors in the mediation of breast cancer metastasis. This is the first paper to suggest that the expression of chemokines and their receptors can determine the metastatic destination of tumour cells. [PubMed: 11242036]

74. Lazennec G, Richmond A. Chemokines and chemokine receptors: new insights into cancer-related inflammation. Trends Mol Med. 2010; 16:133-144. A comprehensive review of the role of chemokines and their receptors in cancer and cancer-associated inflammation. [PubMed: 20163989]

75. Koshiba T, et al. Expression of stromal cell-derived factor 1 and CXCR4 ligand receptor system in pancreatic cancer: a possible role for tumor progression. Clin Cancer Res. 2000; 6:3530-3535. [PubMed: 10999740]

76. Balkwill F. The significance of cancer cell expression of the chemokine receptor CXCR4. Semin Cancer Biol. 2004; 14:171-179. [PubMed: 15246052]

77. Scotton CJ, et al. Multiple actions of the chemokine CXCL12 on epithelial tumor cells in human ovarian cancer. Cancer Res. 2002; 62:5930-5938. [PubMed: 12384559]

78. Ghosh M, et al. Cofilin promotes actin polymerization and defines the direction of cell motility. Science. 2004; 304:743-746. [PubMed: 15118165] 
79. Oser M, et al. Cortactin regulates cofilin and N-WASp activities to control the stages of invadopodium assembly and maturation. J Cell Biol. 2009; 186:571-587. [PubMed: 19704022]

80. Van Goethem E, et al. Macrophage podosomes go 3D. Eur J Cell Biol. 2011; 90:224-236. [PubMed: 20801545]

81. Price LS, Collard JG. Regulation of the cytoskeleton by Rho-family GTPases: implications for tumour cell invasion. Semin Cancer Biol. 2001; 11:167-173. [PubMed: 11322835]

82. Bravo-Cordero JJ, et al. A novel spatiotemporal RhoC activation pathway locally regulates cofilin activity at invadopodia. Curr Biol. 2011; 21:635-644. [PubMed: 21474314]

83. Sarmiento C, et al. WASP family members and formin proteins coordinate regulation of cell protrusions in carcinoma cells. J Cell Biol. 2008; 180:1245-1260. [PubMed: 18362183]

84. Scott RW, et al. LIM kinases are required for invasive path generation by tumor and tumorassociated stromal cells. J Cell Biol. 2010; 191:169-185. [PubMed: 20876278]

85. DesMarais V, Ghosh M, Eddy R, Condeelis J. Cofilin takes the lead. J Cell Sci. 2005; 118:19-26. [PubMed: 15615780]

86. van Rheenen J, et al. EGF-induced PIP2 hydrolysis releases and activates cofilin locally in carcinoma cells. J Cell Biol. 2007; 179:1247-1259. [PubMed: 18086920]

87. Miki H, Yamaguchi H, Suetsugu S, Takenawa T. IRSp53 is an essential intermediate between Rac and WAVE in the regulation of membrane ruffling. Nature. 2000; 408:732-735. [PubMed: 11130076]

88. Abou-Kheir W, Isaac B, Yamaguchi H, Cox D. Membrane targeting of WAVE2 is not sufficient for WAVE2-dependent actin polymerization: a role for IRSp53 in mediating the interaction between Rac and WAVE2. J Cell Sci. 2008; 121:379-390. [PubMed: 18198193]

89. Mader CC, et al. An EGFR-Src-Arg-cortactin pathway mediates functional maturation of invadopodia and breast cancer cell invasion. Cancer Res. 2011; 71:1730-1741. [PubMed: 21257711]

90. Weaver AM, et al. Cortactin promotes and stabilizes Arp2/3-induced actin filament network formation. Curr Biol. 2001; 11:370-374. [PubMed: 11267876]

91. Weaver AM, et al. Interaction of cortactin and N-WASp with Arp2/3 complex. Curr Biol. 2002; 12:1270-1278. [PubMed: 12176354]

92. Yoo SK, et al. Differential regulation of protrusion and polarity by PI3K during neutrophil motility in live zebrafish. Dev Cell. 2010; 18:226-236. [PubMed: 20159593]

93. Andrew N, Insall RH. Chemotaxis in shallow gradients is mediated independently of PtdIns 3kinase by biased choices between random protrusions. Nature Cell Biol. 2007; 9:193-200. [PubMed: 17220879]

94. Bailly M, Yan L, Whitesides GM, Condeelis JS, Segall JE. Regulation of protrusion shape and adhesion to the substratum during chemotactic responses of mammalian carcinoma cells. Exp Cell Res. 1998; 241:285-299. [PubMed: 9637770]

95. Falk DL, et al. Shared, unique and redundant functions of three members of the class I myosins (MyoA, MyoB and MyoF) in motility and chemotaxis in Dictyostelium. J Cell Sci. 2003; 116:3985-3999. [PubMed: 12953059]

96. Chan KT, Bennin DA, Huttenlocher A. Regulation of adhesion dynamics by calpain-mediated proteolysis of focal adhesion kinase (FAK). J Biol Chem. 2010; 285:11418-11426. [PubMed: 20150423]

97. Philippar U, et al. A Mena invasion isoform potentiates EGF-induced carcinoma cell invasion and metastasis. Dev Cell. 2008; 15:813-828. [PubMed: 19081071]

98. Neel NF, et al. VASP is a CXCR2-interacting protein that regulates CXCR2-mediated polarization and chemotaxis. J Cell Sci. 2009; 122:1882-1894. [PubMed: 19435808]

99. Goswami S, et al. Identification of invasion specific splice variants of the cytoskeletal protein Mena present in mammary tumor cells during invasion in vivo. Clin Exp Metastasis. 2009; 26:153-159. [PubMed: 18985426]

100. Curiel TJ, et al. Specific recruitment of regulatory T cells in ovarian carcinoma fosters immune privilege and predicts reduced survival. Nature Med. 2004; 10:942-949. [PubMed: 15322536] 
101. Soria G, Ben-Baruch A. The inflammatory chemokines CCL2 and CCL5 in breast cancer. Cancer Lett. 2008; 267:271-285. [PubMed: 18439751]

102. Fridlender ZG, et al. Polarization of tumor-associated neutrophil phenotype by TGF- $\beta$ : "N1" versus "N2" TAN. Cancer Cell. 2009; 16:183-194. [PubMed: 19732719]

103. Sica A, et al. Macrophage polarization in tumour progression. Semin Cancer Biol. 2008; 18:349355. [PubMed: 18467122]

104. Gu L, et al. Control of $\mathrm{T}_{\mathrm{H}} 2$ polarization by the chemokine monocyte chemoattractant protein-1. Nature. 2000; 404:407-411. [PubMed: 10746730]

105. Tazzyman S, Lewis CE, Murdoch C. Neutrophils: key mediators of tumour angiogenesis. Int J Exp Pathol. 2009; 90:222-231. [PubMed: 19563607]

106. Pollard JW. Macrophages define the invasive microenvironment in breast cancer. J Leukoc Biol. 2008; 84:623-630. [PubMed: 18467655]

107. Sinha P, et al. Proinflammatory S100 proteins regulate the accumulation of myeloid-derived suppressor cells. J Immunol. 2008; 181:4666-4675. [PubMed: 18802069]

108. Joyce JA, Pollard JW. Microenvironmental regulation of metastasis. Nature Rev Cancer. 2009; 9:239-252. [PubMed: 19279573]

109. Gabrilovich DI, Nagaraj S. Myeloid-derived suppressor cells as regulators of the immune system. Nature Rev Immunol. 2009; 9:162-174. [PubMed: 19197294]

110. Mantovani A, et al. The chemokine system in cancer biology and therapy. Cytokine Growth Factor Rev. 2009; 21:27-39. References 108-110 are comprehensive reviews about how chemokines influence the tumour microenvironment. [PubMed: 20004131]

111. Folkman J. Role of angiogenesis in tumor growth and metastasis. Semin Oncol. 2002; 29:15-18. [PubMed: 12516034]

112. Salcedo R, et al. Eotaxin (CCL11) induces in vivo angiogenic responses by human CCR3 ${ }^{+}$ endothelial cells. J Immunol. 2001; 166:7571-7578. [PubMed: 11390513]

113. Mehrad B, Keane MP, Strieter RM. Chemokines as mediators of angiogenesis. Thromb Haemost. 2007; 97:755-762. [PubMed: 17479186]

114. Kryczek I, et al. CXCL12 and vascular endothelial growth factor synergistically induce neoangiogenesis in human ovarian cancers. Cancer Res. 2005; 65:465-472. [PubMed: 15695388]

115. Orimo A, et al. Stromal fibroblasts present in invasive human breast carcinomas promote tumor growth and angiogenesis through elevated SDF-1/CXCL12 secretion. Cell. 2005; 121:335-348. This study demonstrates that CXCL12, which is secreted by CAFs, mediates the recruitment of EPCs to promote angiogenesis and growth in primary breast tumours. [PubMed: 15882617]

116. Chen $\mathrm{H}$, et al. Pleiotrophin produced by multiple myeloma induces transdifferentiation of monocytes into vascular endothelial cells: a novel mechanism of tumor-induced vasculogenesis. Blood. 2009; 113:1992-2002. [PubMed: 19060246]

117. Nozawa H, Chiu C, Hanahan D. Infiltrating neutrophils mediate the initial angiogenic switch in a mouse model of multistage carcinogenesis. Proc Natl Acad Sci USA. 2006; 103:12493-12498. [PubMed: 16891410]

118. Ostman A, Augsten M. Cancer-associated fibroblasts and tumor growth — bystanders turning into key players. Curr Opin Genet Dev. 2009; 19:67-73. [PubMed: 19211240]

119. Ben-Baruch A. Organ selectivity in metastasis: regulation by chemokines and their receptors. Clin Exp Metastasis. 2008; 25:345-356. [PubMed: 17891505]

120. Koizumi K, Hojo S, Akashi T, Yasumoto K, Saiki I. Chemokine receptors in cancer metastasis and cancer cell-derived chemokines in host immune response. Cancer Sci. 2007; 98:1652-1658. [PubMed: 17894551]

121. Chambers AF, Groom AC, MacDonald IC. Dissemination and growth of cancer cells in metastatic sites. Nature Rev Cancer. 2002; 2:563-572. [PubMed: 12154349]

122. Condeelis J, Pollard JW. Macrophages: obligate partners for tumor cell migration, invasion, and metastasis. Cell. 2006; 124:263-266. [PubMed: 16439202]

123. Wyckoff $\mathrm{J}$, et al. A paracrine loop between tumor cells and macrophages is required for tumor cell migration in mammary tumors. Cancer Res. 2004; 64:7022-7029. A seminal paper 
demonstrating that a paracrine interaction between macrophages and breast tumour cells is required for in vivo invasion and metastasis. [PubMed: 15466195]

124. Kacinski BM. CSF-1 and its receptor in breast carcinomas and neoplasms of the female reproductive tract. Mol Reprod Dev. 1997; 46:71-74. [PubMed: 8981366]

125. Patsialou A, et al. Invasion of human breast cancer cells in vivo requires both paracrine and autocrine loops involving the colony-stimulating factor-1 receptor. Cancer Res. 2009; 69:94989506. [PubMed: 19934330]

126. Hernandez L, et al. The EGF/CSF-1 paracrine invasion loop can be triggered by heregulin- $\beta 1$ and CXCL12. Cancer Res. 2009; 69:3221-3227. [PubMed: 19293185]

127. Wyckoff JB, et al. Direct visualization of macrophage-assisted tumor cell intravasation in mammary tumors. Cancer Res. 2007; 67:2649-2656. [PubMed: 17363585]

128. Entenberg D, et al. Set up and use of a two laser multiphoton microscope for multichannel intravital fluorescence imaging. Nature Protoc. 201110.1038/nprot.2011.376

129. Roussos ET, et al. Mena deficiency delays tumor progression and decreases metastasis in polyoma middle-T transgenic mouse mammary tumors. Breast Cancer Res. 2010; 12:R101. [PubMed: 21108830]

130. Robinson BD, et al. Tumor microenvironment of metastasis in human breast carcinoma: a potential prognostic marker linked to hematogenous dissemination. Clin Cancer Res. 2009; 15:2433-2441. This study demonstrates that the density of TMEM predicts the development of systemic, haematogenous metastases in human breast tumours. These findings highlight the clinical relevance of chemotaxis-mediated streaming between tumour cells and macrophages, which was previously observed in mouse models. [PubMed: 19318480]

131. Roussos ET, et al. Mena invasive (Mena ${ }^{\mathrm{INV}}$ ) and Mena11a isoforms play distinct roles in breast cancer cell cohesion and association with TMEM. Clin Exp Metastasis. Apr 12.2011 10.1007/ s10585-011-9388-9386

132. Gerber PA, Hippe A, Buhren BA, Muller A, Homey B. Chemokines in tumor-associated angiogenesis. Biol Chem. 2009; 390:1213-1223. [PubMed: 19804363]

133. Lurje $\mathrm{G}$, et al. Genetic variations in angiogenesis pathway genes associated with clinical outcome in localized gastric adenocarcinoma. Ann Oncol. 2009; 21:78-86. [PubMed: 19622587]

134. Wang W, et al. Identification and testing of a gene expression signature of invasive carcinoma cells within primary mammary tumors. Cancer Res. 2004; 64:8585-8594. [PubMed: 15574765]

135. Wang W, et al. Coordinated regulation of pathways for enhanced cell motility and chemotaxis is conserved in rat and mouse mammary tumors. Cancer Res. 2007; 67:3505-3511. [PubMed: 17440055]

136. Kang Y, et al. A multigenic program mediating breast cancer metastasis to bone. Cancer Cell. 2003; 3:537-549. [PubMed: 12842083]

137. Minn AJ, et al. Genes that mediate breast cancer metastasis to lung. Nature. $2005 ; 436: 518-524$. [PubMed: 16049480]

138. Ellis L, Hammers H, Pili R. Targeting tumor angiogenesis with histone deacetylase inhibitors. Cancer Lett. 2009; 280:145-153. [PubMed: 19111391]

139. Miller K, et al. Paclitaxel plus bevacizumab versus paclitaxel alone for metastatic breast cancer. N Engl J Med. 2007; 357:2666-2676. [PubMed: 18160686]

140. Hurwitz $\mathrm{H}$. Integrating the anti-VEGF-A humanized monoclonal antibody bevacizumab with chemotherapy in advanced colorectal cancer. Clin Colorectal Cancer. 2004; 4:S62-S68. [PubMed: 15479481]

141. Huang S, et al. Fully humanized neutralizing antibodies to interleukin-8 (ABX-IL8) inhibit angiogenesis, tumor growth, and metastasis of human melanoma. Am J Pathol. 2002; 161:125134. [PubMed: 12107097]

142. Mian BM, et al. Fully human anti-interleukin 8 antibody inhibits tumor growth in orthotopic bladder cancer xenografts via down-regulation of matrix metalloproteases and nuclear factor- $\mathrm{kB}$. Clin Cancer Res. 2003; 9:3167-3175. [PubMed: 12912969]

143. Husemann Y, et al. Systemic spread is an early step in breast cancer. Cancer Cell. 2008; 13:5868. [PubMed: 18167340] 
144. Goss PE, Chambers AF. Does tumour dormancy offer a therapeutic target? Nature Rev Cancer. 2010; 10:871-877. [PubMed: 21048784]

145. Kim MY, et al. Tumor self-seeding by circulating cancer cells. Cell. 2009; 139:1315-1326. This is the first demonstration that tumour cells from secondary metastasis can seed back to the permissive microenvironment of the primary tumour. This study could have major implications for the role of tumour cell dissemination from secondary deposits or micrometastases in patients after the resection of the primary tumour. [PubMed: 20064377]

146. Pantel K, Alix-Panabieres C. Circulating tumour cells in cancer patients: challenges and perspectives. Trends Mol Med. 2011; 16:398-406. [PubMed: 20667783]

147. Cristofanilli M, et al. Circulating tumor cells, disease progression, and survival in metastatic breast cancer. N Engl J Med. 2004; 351:781-791. [PubMed: 15317891]

148. Cohen SJ, et al. Prognostic significance of circulating tumor cells in patients with metastatic colorectal cancer. Ann Oncol. 2009; 20:1223-1229. [PubMed: 19282466]

149. Rack BK, et al. Use of circulating tumor cells (CTC) in peripheral blood of breast cancer patients before and after adjuvant chemotherapy to predict risk of relapse: the SUCCESS trial. J Clin Oncol. 2010; 28(Suppl):Abstract 1003.

150. Sleeman J, Steeg PS. Cancer metastasis as a therapeutic target. Eur J Cancer. 2010; 46:11771180. [PubMed: 20307970]

151. Steeg PS. Tumor metastasis: mechanistic insights and clinical challenges. Nature Med. 2006; 12:895-904. References 150 and 151 are comprehensive reviews about how dissemination and metastasis should be considered as clinically relevant targets for cancer therapy. [PubMed: 16892035]

152. Wiegand S, Kruse J, Gronemann S, Hammann C. Efficient generation of gene knockout plasmids for Dictyostelium discoideum using one-step cloning. Genomics. 2011; 97:321-325. [PubMed: 21316445]

153. Koonce MP, Graf R. Dictyostelium discoideum: a model system for ultrastructural analyses of cell motility and development. Methods Cell Biol. 2010; 96:197-216. [PubMed: 20869524]

154. Williams JG. Dictyostelium finds new roles to model. Genetics. 2010; 185:717-726. [PubMed: 20660652]

155. Whitney TJ, Gardner DG, Mott ML, Brandon M. Identifying the molecular basis of functions in the transcriptome of the social amoeba Dictyostelium discoideum. Genet Mol Res. 2010; 9:394415. [PubMed: 20309825]

156. van Hemert F, Lazova MD, Snaar-Jagaska BE, Schmidt T. Mobility of G proteins is heterogeneous and polarized during chemotaxis. J Cell Sci. 2010; 123:2922-2930. [PubMed: 20682639]

157. Stephens L, Milne L, Hawkins P. Moving towards a better understanding of chemotaxis. Curr Biol. 2008; 18:R485-R494. [PubMed: 18522824]

158. Alvarez-Curto E, et al. cAMP production by adenylyl cyclase $\mathrm{G}$ induces prespore differentiation in Dictyostelium slugs. Development. 2007; 134:959-966. [PubMed: 17267449]

159. Charest PG, et al. A Ras signaling complex controls the RasC-TORC2 pathway and directed cell migration. Dev Cell. 2010; 18:737-749. [PubMed: 20493808]

160. Cai H, et al. Ras-mediated activation of the TORC2-PKB pathway is critical for chemotaxis. J Cell Biol. 2010; 190:233-245. [PubMed: 20660630]

161. Liu L, Das S, Losert W, Parent C. A mTORC2 regulates neutrophil chemotaxis in a cAMP- and RhoA-dependent fashion. Dev Cell. 2010; 19:845-857. [PubMed: 21145500]

162. Kay RR, Langridge P, Traynor D, Hoeller O. Changing directions in the study of chemotaxis. Nature Rev Mol Cell Biol. 2008; 9:455-463. [PubMed: 18500256]

163. Iglesias PA. Spatial regulation of PI3K signaling during chemotaxis. Wiley Interdiscip Rev Syst Biol Med. 2009; 1:247-253. [PubMed: 20835994]

164. Rericha EC, Parent CA. Steering in quadruplet: the complex signaling pathways directing chemotaxis. Sci Signal. 2008; 1:pe26. [PubMed: 18523238]

165. Comer FI, Parent CA. PI 3-kinases and PTEN: how opposites chemoattract. Cell. 2002; 109:541544. [PubMed: 12062096] 
166. Funamoto S, Meili R, Lee S, Parry L, Firtel RA. Spatial and temporal regulation of 3phosphoinositides by PI 3-kinase and PTEN mediates chemotaxis. Cell. 2002; 109:611-623. [PubMed: 12062104]

167. Huang YE, et al. Receptor-mediated regulation of PI3Ks confines $\mathrm{PI}(3,4,5) \mathrm{P}_{3}$ to the leading edge of chemotaxing cells. Mol Biol Cell. 2003; 14:1913-1922. [PubMed: 12802064]

168. Hannigan M, et al. Neutrophils lacking phosphoinositide 3-kinase- $\gamma$ show loss of directionality during N-formyl-Met-Leu-Phe-induced chemotaxis. Proc Natl Acad Sci USA. 2002; 99:36033608. [PubMed: 11904423]

169. Loovers HM, et al. Distinct roles of $\mathrm{PI}(3,4,5) \mathrm{P}_{3}$ during chemoattractant signaling in Dictyostelium: a quantitative in vivo analysis by inhibition of PI3-kinase. Mol Biol Cell. 2006; 17:1503-1513. [PubMed: 16421252]

170. Yip SC, et al. The distinct roles of Ras and Rac in PI 3-kinase-dependent protrusion during EGFstimulated cell migration. J Cell Sci. 2007; 120:3138-3146. [PubMed: 17698922]

171. Soon LL. A discourse on cancer cell chemotaxis: where to from here? IUBMB Life. 2007; 59:6067. [PubMed: 17454296]

172. Siegert F, Weijer CJ. Three-dimensional scroll waves organize Dictyostelium slugs. Proc Natl Acad Sci USA. 1992; 89:6433-6437. [PubMed: 1631140]

173. Killich T, et al. The locomotion, shape and pseudopodial dynamics of unstimulated Dictyostelium cells are not random. J Cell Sci. 1993; 106:1005-1013. [PubMed: 7510298]

174. Friedl P, Borgmann S, Brocker EB. Amoeboid leukocyte crawling through extracellular matrix: lessons from the Dictyostelium paradigm of cell movement. J Leukoc Biol. 2001; 70:491-509. [PubMed: 11590185] 


\section{At a glance}

- Chemotaxis is the phenomenon by which cell movement is directed in response to an extracellular chemical gradient. Factors that mediate chemotaxis are frequently mutated in cancer. Although most of the factors have dual roles in cell growth and survival, they also mediate cytoskeletal dynamics that results in chemotaxis, thus suggesting a potentially important role of chemotaxis in cancer.

- Tumour cells in vivo can move both randomly and directionally. However, invasion, migration and dissemination are most efficient when the cell is involved in directed migration. Different modes of directed migration have been described for tumour cells (amoeboid migration or mesenchymal migration for single cells and collective or streaming migration for groups of cells). The occurrence and frequency of these modes of migration in cancer is dependent on the type of cancer and the surrounding factors within the tumour microenvironment.

- Despite the various patterns of directed migration during tumour cell dissemination, the intracellular processes that direct the cell motility cycle in response to the chemoattractant are probably similar and are comprised of three steps: chemosensing, polarization and locomotion. First, polarized intracellular signals lead to asymmetric actin polymerization resulting in extension of the cell membrane in the direction of movement, thus creating the leading-edge protrusion. This is followed by integrin-mediated adhesion to the substrate on which the cell is moving, and then by detachment from the substrate and contraction of the trailing edge of the cell.

- In addition to cancer cells, directional migration to a chemokine source is observed in stromal cells, which frequently shape the tumour microenvironment to a more pro-metastatic state. A complex network of chemokines and growth factors is involved in the communication of tumour cells with stromal cells. This leads to several major events of cancer progression, such as immune evasion, angiogenesis, invasion and dissemination.

- Despite the strong experimental evidence for the involvement of chemotaxis signalling pathways in tumour cell dissemination, therapeutics under development are tested only for their ability to reduce the tumour size in patients with late-stage disease. A lack of relevant therapeutic end points in clinical practice, together with the current belief that dissemination occurs early in tumour progression, before clinical presentation, have brought scepticism to the development of anti-invasion and anti-dissemination drugs.

- We speculate that dissemination is not only a feasible but also a necessary therapeutic target if efficient long-term management of minimal residual disease is a goal in cancer treatment. The identification of therapeutic end points 
relevant to tumour cell dissemination will facilitate the development and appropriate use of therapeutics. 


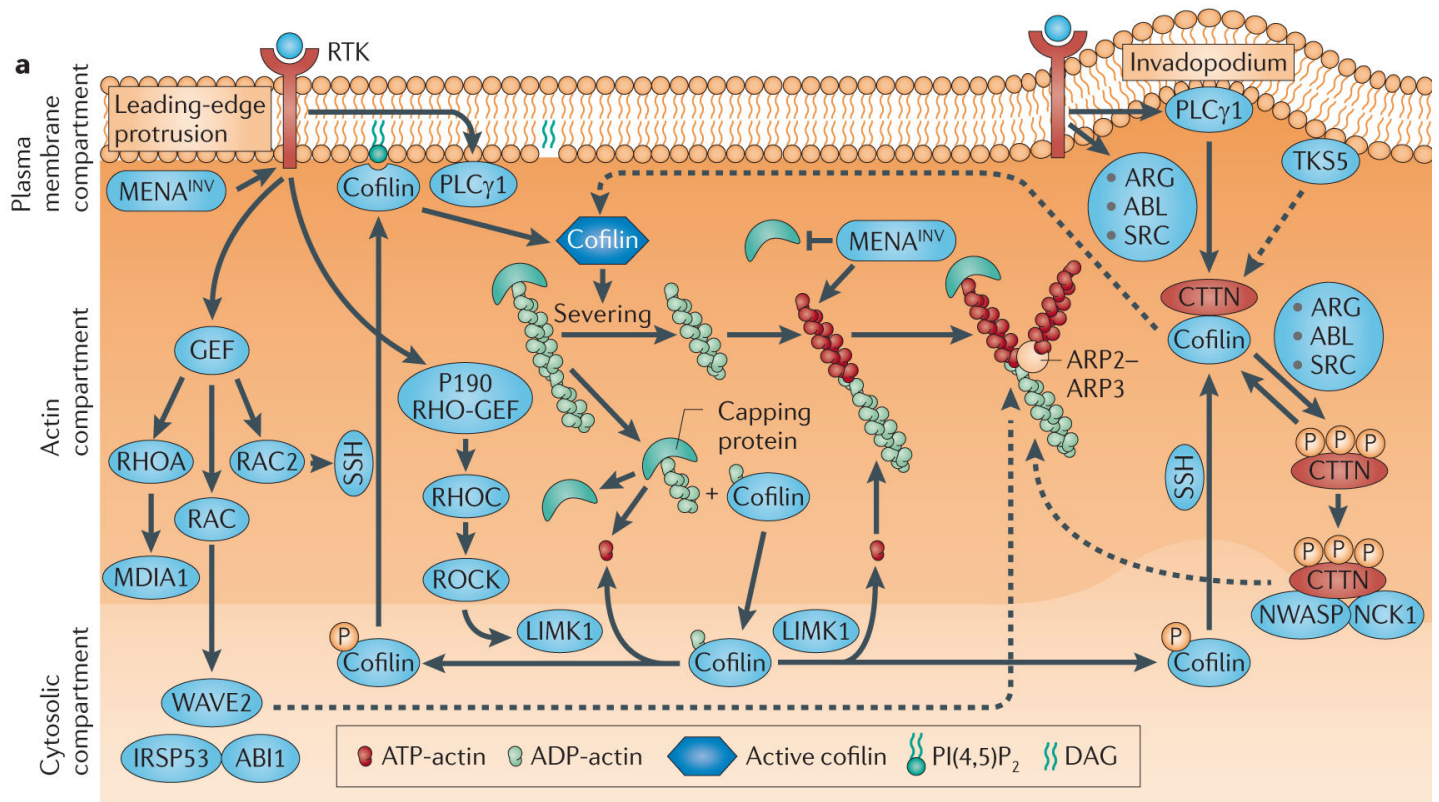

b

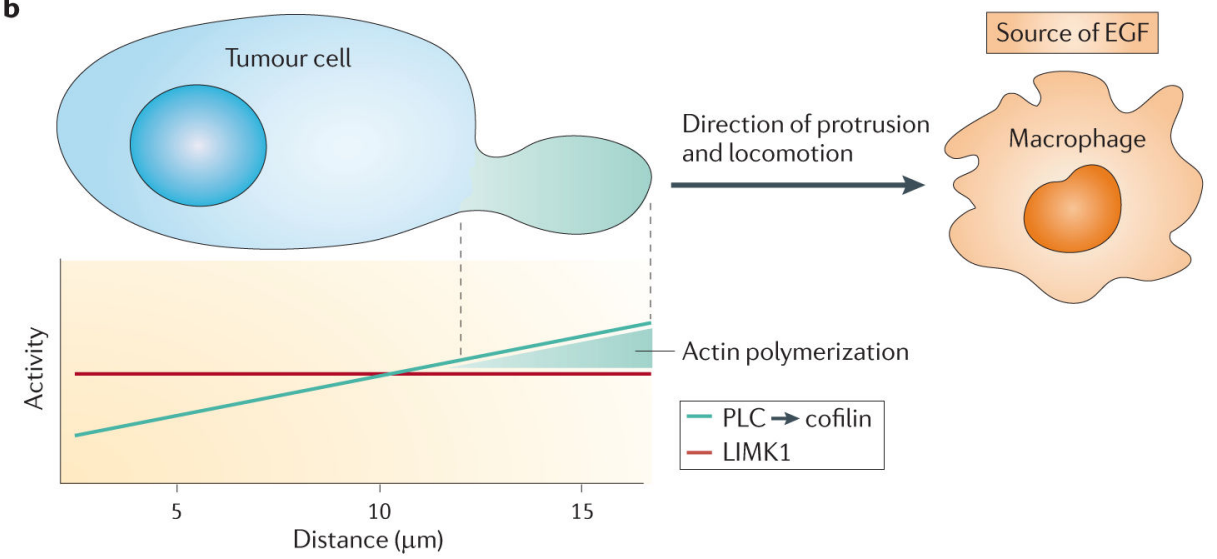

Figure 1. Regulation of chemotaxis in tumour cells

a $\mid$ The common cofilin activity cycle in lamellipodia and invadopodia. Different pathways regulating cofilin activity in the leading-edge protrusion (left side of the figure) and invadopodium (right side of the figure) are shown. The plasma membrane at the leadingedge protrusion is enriched with phosphatidylinositol 4,5-bisphosphate $\left(\mathrm{PI}(4,5) \mathrm{P}_{2}\right)$, and the loss of binding of cofilin to $\mathrm{PI}(4,5) \mathrm{P}_{2}$ is the primary mechanism that is used to initiate cofilin activity at the leading edge. In invadopodia, the loss of binding of cofilin to cortactin (CTTN) is the primary mechanism used to initiate cofilin activity. New actin filaments resulting from cofilin activity support dendritic nucleation (the formation of actin branches) from the actin-related protein 2 (ARP2)-ARP3 complex, which is a common feature of both lamellipodia and invadopodia. $\mathbf{b}$ | The local excitation-global inhibition (LEGI) model of chemotaxis as applied to the cofilin activity cycle. Asymmetric actin polymerization (green shading) results when the asymmetric activation of cofilin (green line, which follows the concentration gradient of epidermal growth factor (EGF)) is further focused by global activation of LIM domain kinase 1 (LIMK1) (red line). LIMK1 inhibits cofilin activity globally but not fully on the side of the cell facing the chemotactic signal. The cell shown 
above the graph represents an example of the LEGI model, whereby a tumour cell protrudes towards a gradient of EGF that is secreted by a macrophage. As a result of this stimulation there is local asymmetric excitation of cofilin, which leads to asymmetric actin polymerization in the leading-edge protrusion (green shading), and global activation of LIMK1 within the whole cell, which results in locomotion in the direction of the arrow. ABI1, ABL-interactor 1; ARG, Abelson-related gene; DAG, diacylglycerol; GEF, guanine nucleotide exchange factor; IRSP53, insulin receptor substrate p53; MDIA1, mammalian diaphanous homologue 1; MENA, mammalian enabled homologue (also known as ENAH); NCK1, NCK adaptor protein 1; NWASP, neural Wiskott-Aldrich syndrome protein; PLC $\gamma 1$, phospholipase $\mathrm{C} \gamma 1$; ROCK, RHO-associated coiled-coil-containing protein kinase; RTK, receptor tyrosine kinase; SSH, slingshot homologue; TKS5, tyrosine kinase substrate with five SH3 domains; WAVE2, WASP family verprolin homologous protein 2. 


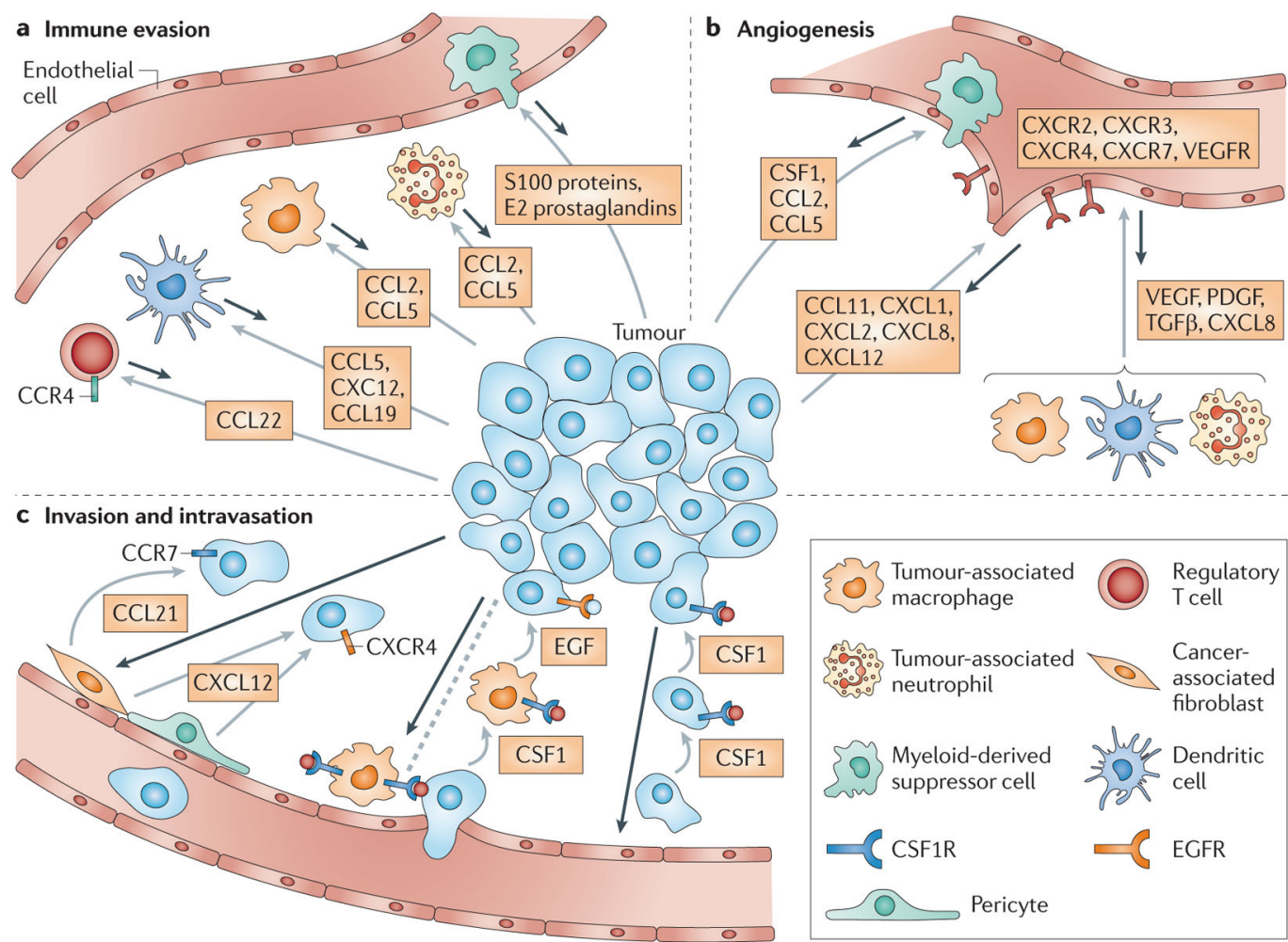

Figure 2. Chemotaxis shapes the tumour microenvironment

A simplified schematic of the tumour microenvironment and the roles of chemotaxis in the processes of: immune evasion (a), angiogenesis (b) and invasion and intravasation (c) in cancer. Grey arrows indicate the gradient direction of chemotactic factors: from the cell that secretes to the cell that responds to the factor. Black arrows indicate the direction of cell migration. The dashed grey line indicates matrix fibres along which cells migrate. CSF1, colony-stimulating factor 1; CSF1R, CSF1 receptor; EGF, epidermal growth factor; EGFR, EGF receptor; PDGF, platelet-derived growth factor; TGF $\beta$, transforming growth factor- $\beta$; VEGF, vascular endothelial growth factor; VEGFR, VEGF receptor. 

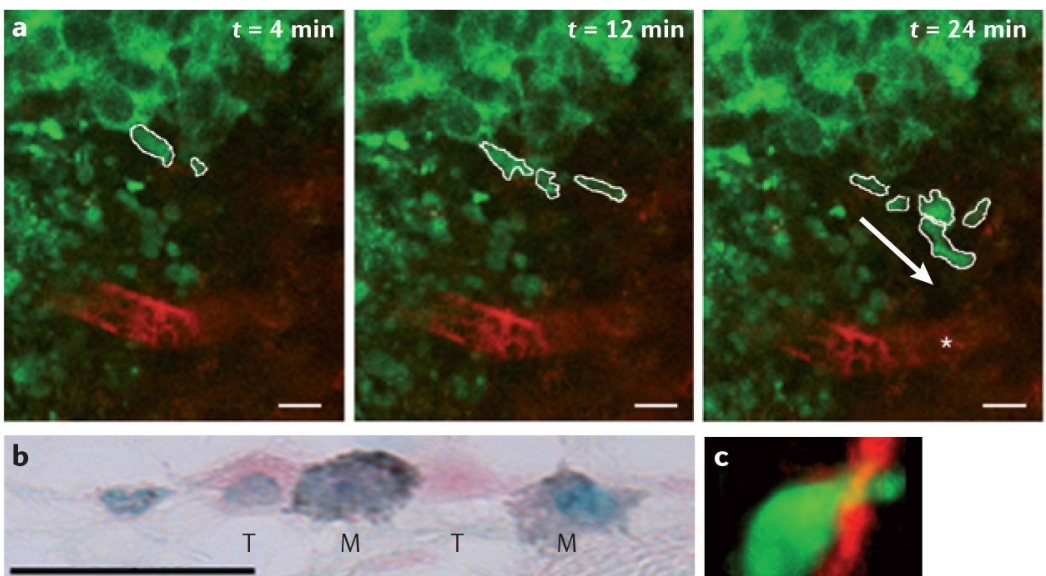

c
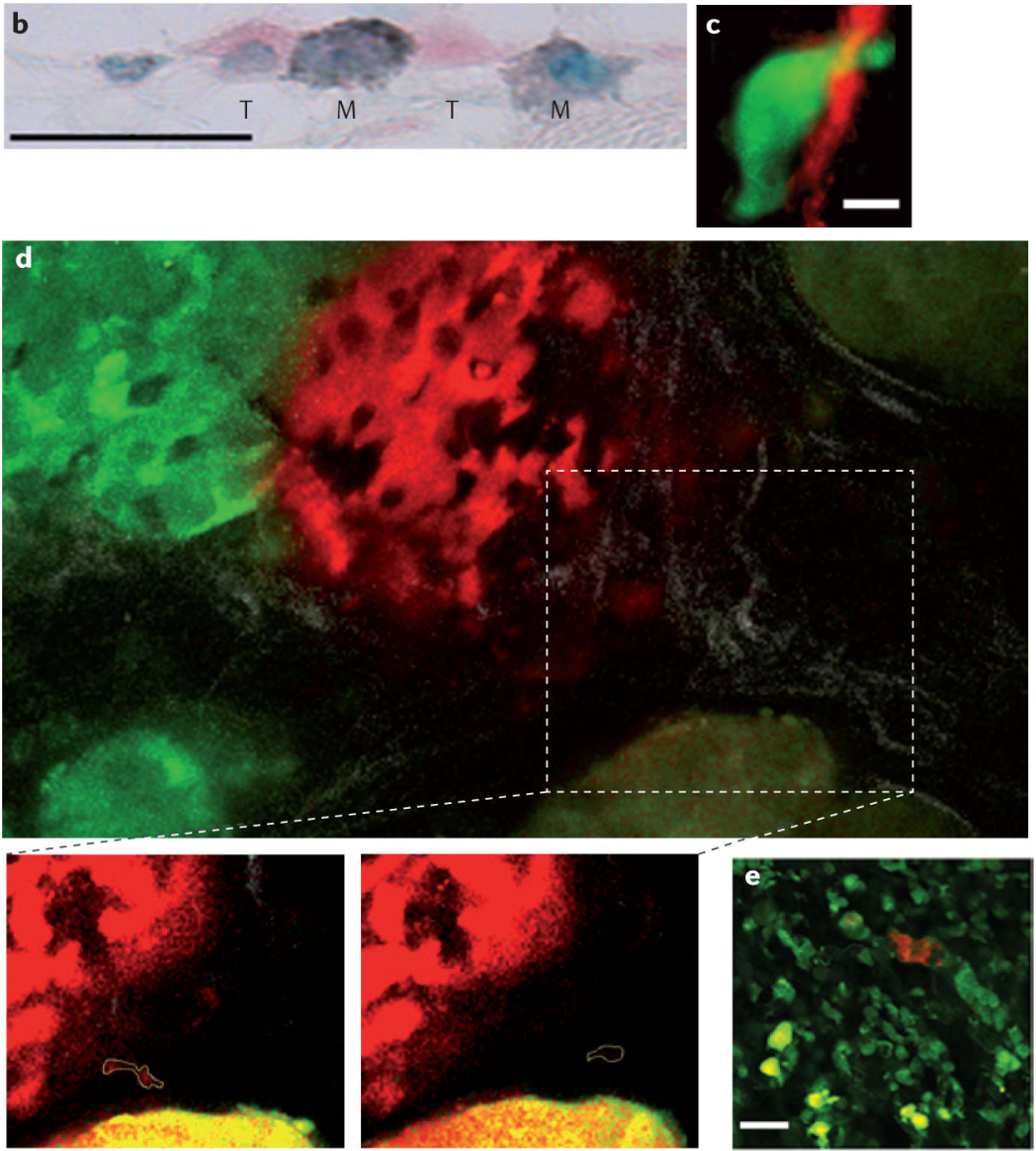

Figure 3. Observations of streaming, intravasation and dissemination of tumour cells in mammary tumours

a In vivo multiphoton microscopy of mammary primary tumours in mice (from REF. 5).

MTLn3 rat breast adenocarcinoma cells, engineered to express a fusion protein comprised of enhanced green fluorescent protein (EGFP)-mammalian enabled homologue invasive splice variant (MENA ${ }^{\mathrm{INV}}$; green), move in a multicellular stream towards a blood vessel (red) over 30 minutes. Scale bar $=25 \mu \mathrm{m}$. The white arrow indicates the direction of cell movement. The asterisk indicates the location of the blood vessel. See also Supplementary information S2 (movie). b | Immunohistochemistry of a fixed and paraffin-embedded MTLn3 primary tumour with tumour cells overexpressing MENA ${ }^{\text {INV }}$ (T; pink) and F4/80-expressing macrophages (M; grey), imaged at x63 magnification (from REF. 5). Nuclear counterstain is 
shown in green. Scale bar $=20 \mu \mathrm{m}$. $\mathbf{c} \mid$ A tumour cell expressing EGFP (green) crossing the endothelium (red) of a blood vessel in a mammary tumour. Scale bar $=5 \mu \mathrm{m}$. Image courtesy of J. van Rheenen, J. Wyckoff and J.S.C., Albert Einstein College of Medicine. d | Photoconversion of dendra-expressing tumour cells from green to red allows the red tumour cells to be followed as they actively exit the primary tumour via blood vessels, with knowledge of their origin. $\mathbf{e}$ | Red photoconverted tumour cells arrive at the lung and remain there as either a disseminated non-dividing population (red) or as a dividing population (yellow). Scale bar $=25 \mu \mathrm{m}$. Parts $\mathbf{d}$ and $\mathbf{e}$ are reproduced, with permission, from REF. 128 (C) (2011) Macmillan Publishers Ltd. All rights reserved. 


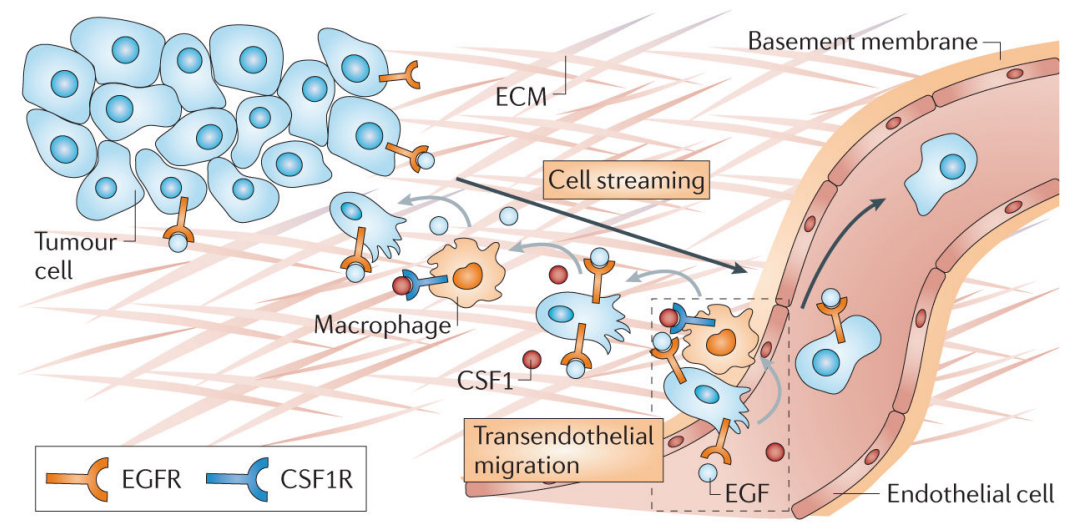

Figure 4. Multicellular streaming of tumour cells and macrophages leading to intravasation in mammary tumours

Both streaming migration and intravasation require macrophages. In the metastatic tumour microenvironment shown, initiation of chemotaxis to epidermal growth factor (EGF) that is supplied by macrophages promotes colony-stimulating factor 1 (CSF1) production by tumour cells. Macrophages chemotax towards CSF1, resulting in relay chemotaxis between the two cell types. Relay chemotaxis results in paracrine-dependent carcinoma cell streaming and transendothelial migration. The close proximity of invasive tumour cells, macrophages and endothelial cells leads to the formation of the tumour microenvironment of metastasis (TMEM; dashed box), which has also been found as an anatomical landmark in tumour tissues from patients with breast cancer ${ }^{130}$. Black arrows indicate the direction of cell migration, grey arrows indicate the gradient direction of chemotactic factors: from the cell that secretes to the cell that responds to the factor. CSF1R, CSF1 receptor; ECM, extracellular matrix; EGFR, EGF receptor. 
Table 1

Chemokines and growth factors involved in chemotaxis in cancer

\begin{tabular}{|c|c|c|c|}
\hline $\begin{array}{l}\text { Chemokine or growth } \\
\text { factor }\end{array}$ & $\begin{array}{l}\text { Chemokine receptor or } \\
\text { growth factor receptor }\end{array}$ & $\begin{array}{l}\text { Experimental evidence for chemotaxis } \\
\text { in cancer }\end{array}$ & Types of cancer affected \\
\hline $\begin{array}{l}\text { CXCL12 (also known as } \\
\text { SDF1) }\end{array}$ & CXCR4 & $\begin{array}{ll}\text { - } & \begin{array}{l}\text { Transwell assay (Boyden } \\
\text { chamber) }\end{array} \\
\text { - } & \text { In vivo invasion assay } \\
\text { - } & \begin{array}{l}\text { In vivo recruitment of bone } \\
\text { marrow-derived cells }\end{array}\end{array}$ & $\begin{array}{l}\text { Breast, prostate, ovarian, pancreatic, } \\
\text { colorectal, renal and gastric cancers, } \\
\text { melanoma, NSCLC, } \\
\text { rhabdomyosarcoma and Ewing's } \\
\text { sarcoma }\end{array}$ \\
\hline CCL19 and CCL21 & CCR7 & Transwell assay (Boyden chamber) & $\begin{array}{l}\text { Breast, cervical and lung cancers, } \\
\text { leukaemia and squamous cell } \\
\text { carcinoma }\end{array}$ \\
\hline CCL22 & CCR4 & $\begin{array}{ll}\text { - } & \begin{array}{l}\text { Transwell assay (Boyden } \\
\text { chamber) }\end{array} \\
\text { - } \quad \text { In vivo recruitment of T cells } \\
\text { and other immune cells }\end{array}$ & $\begin{array}{l}\text { Breast, ovarian and gastric cancers } \\
\text { and leukaemia }\end{array}$ \\
\hline $\begin{array}{l}\text { CX3CL1 (also known as } \\
\text { fractalkine) }\end{array}$ & CX3CR1 & $\begin{array}{ll}\text { - } & \begin{array}{l}\text { Transwell assay (Boyden } \\
\text { chamber) }\end{array} \\
\text { - } \quad \text { In vivo recruitment of NK } \\
\text { cells and other immune cells }\end{array}$ & $\begin{array}{l}\text { Pancreatic, prostate and lung cancers } \\
\text { and neuroblastoma }\end{array}$ \\
\hline $\begin{array}{l}\text { CCL5 (also known as } \\
\text { RANTES), CCL2 (also } \\
\text { known as MCP1), CCL3 } \\
\text { (also known as MIP1a) } \\
\text { and CCL7 (also known as } \\
\text { MCP3) }\end{array}$ & CCR1 & $\begin{array}{ll}\text { - } & \begin{array}{l}\text { Transwell assay (Boyden } \\
\text { chamber) }\end{array} \\
\text { - } & \begin{array}{l}\text { In vivo recruitment of T cells } \\
\text { and other immune cells }\end{array}\end{array}$ & $\begin{array}{l}\text { Colorectal cancer, hepatocellular } \\
\text { carcinoma and melanoma }\end{array}$ \\
\hline CCL25 & CCR9 & Transwell assay (Boyden chamber) & Melanoma and leukaemia \\
\hline $\begin{array}{l}\text { CXCL1, CXCL5, CXCL6 } \\
\text { and CXCL8 }\end{array}$ & CXCR1 and CXCR2 & $\begin{array}{ll}\text { - } & \begin{array}{l}\text { Transwell assay (Boyden } \\
\text { chamber) }\end{array} \\
\text { - } & \text { Wound-healing assay }\end{array}$ & $\begin{array}{l}\text { Colorectal, head and neck and } \\
\text { prostate cancers, melanoma and } \\
\text { leukaemia }\end{array}$ \\
\hline $\begin{array}{l}\text { EGF, TGFa, betacellulin, } \\
\text { HBEGF, amphiregulin and } \\
\text { heregulin (also known as } \\
\text { NRG1) }\end{array}$ & $\begin{array}{l}\text { EGFR (also known as } \\
\text { ERBB1), ERBB2 (also } \\
\text { known as HER2), } \\
\text { ERBB3 and ERBB4 }\end{array}$ & $\begin{array}{ll}\text { - } & \begin{array}{l}\text { Transwell assay (Boyden } \\
\text { chamber) }\end{array} \\
\text { - } & \text { Pipette-following } \\
\text { - } & \text { Dunn chamber } \\
\text { - } & \text { 3D invasion } \\
\text { - } & \text { In vivo invasion } \\
\text { - } & \text { Intravital imaging }\end{array}$ & $\begin{array}{l}\text { Breast, lung, colorectal and gastric } \\
\text { cancers, glioblastoma, mesothelioma } \\
\text { and neurofibromatosis }\end{array}$ \\
\hline FGF & FGFR1-4 & $\begin{array}{ll}\text { - } & \begin{array}{l}\text { Transwell assay (Boyden } \\
\text { chamber) }\end{array} \\
\text { - } & \text { Wound-healing assay }\end{array}$ & $\begin{array}{l}\text { Breast, ovarian, pancreatic and renal } \\
\text { cancers, glioblastoma and Ewing's } \\
\text { sarcoma }\end{array}$ \\
\hline PDGF & PDGFR & $\begin{array}{ll}\text { - } & \begin{array}{l}\text { Transwell assay (Boyden } \\
\text { chamber) }\end{array} \\
\text { - } & 3 \mathrm{D} \text { culture } \\
\text { - } & \begin{array}{l}\text { In vivo recruitment of } \\
\text { pericytes }\end{array}\end{array}$ & $\begin{array}{l}\text { Breast cancer, glioblastoma, } \\
\text { mesolthelioma and melanoma }\end{array}$ \\
\hline
\end{tabular}




\begin{tabular}{|c|c|c|c|}
\hline $\begin{array}{l}\text { Chemokine or growth } \\
\text { factor }\end{array}$ & $\begin{array}{l}\text { Chemokine receptor or } \\
\text { growth factor receptor }\end{array}$ & $\begin{array}{l}\text { Experimental evidence for chemotaxis } \\
\text { in cancer }\end{array}$ & Types of cancer affected \\
\hline TGF $\beta$ & TGF $\beta$ R1 and TGF $\beta R 2$ & $\begin{array}{ll}\text { - } & \begin{array}{l}\text { Transwell assay (Boyden } \\
\text { chamber) }\end{array} \\
\text { - } & \text { Dunn chamber } \\
\text { - } & \text { Wound-healing assay } \\
\text { - } & \text { Intravital imaging }\end{array}$ & $\begin{array}{l}\text { Breast, lung, squamous cell and } \\
\text { oesophageal cancers }\end{array}$ \\
\hline IGF1 & IGF1R & $\begin{array}{ll} & \begin{array}{l}\text { Transwell assay (Boyden } \\
\text { chamber) }\end{array} \\
\text { - } & \text { Wound-healing assay }\end{array}$ & $\begin{array}{l}\text { Breast cancer, sarcoma, multiple } \\
\text { myeloma, lymphoma, } \\
\text { choriocarcinoma, mesothelioma and } \\
\text { melanoma }\end{array}$ \\
\hline $\begin{array}{l}\text { CSF1 (also known as } \\
\text { MCSF) }\end{array}$ & CSF1R & $\begin{array}{ll}\text { - } & \begin{array}{l}\text { Transwell assay (Boyden } \\
\text { chamber) }\end{array} \\
\text { - } & \text { Dunn chamber } \\
\text { - } & \text { 3D invasion } \\
\text { - } & \text { In vivo invasion } \\
\text { - } & \text { Intravital imaging }\end{array}$ & $\begin{array}{l}\text { Breast, ovarian, endometrial, prostate } \\
\text { and gastric cancers and leukaemia }\end{array}$ \\
\hline VEGFA and VEGFC & VEGFR1-3 & $\begin{array}{ll}\text { - } & \begin{array}{l}\text { Transwell assay (Boyden } \\
\text { chamber) }\end{array} \\
\text { - } & \text { 3D culture }\end{array}$ & $\begin{array}{l}\text { Melanoma, prostate cancer, sarcoma, } \\
\text { meningioma and leukaemia }\end{array}$ \\
\hline
\end{tabular}

For a more comprehensive version of this table, with information on therapeutic compounds in development for the above factors, as well as references, see Supplementary information S1 (table). 3D, three-dimensional; CSF1, colony-stimulating factor 1; CSF1R, CSF1 receptor; EGF, epidermal growth factor; EGFR, EGF receptor; FGF, fibroblast growth factor; FGFR, FGF receptor; HBEGF, heparin-binding EGF-like growth factor; IGF1, insulin-like growth factor 1; IGF1R, IGF1 receptor; MCP, monocyte chemoattractant protein; MIP1, macrophage inflammatory protein 1; NK, natural killer; NSCLC, non-small-cell lung cancer; PDGF, platelet-derived growth factor; PDGFR, PDGF receptor; TGF, transforming growth factor; TGF $\beta$, TGF $\beta$ receptor; VEGF, vascular endothelial growth factor; VEGFR, VEGF receptor. 

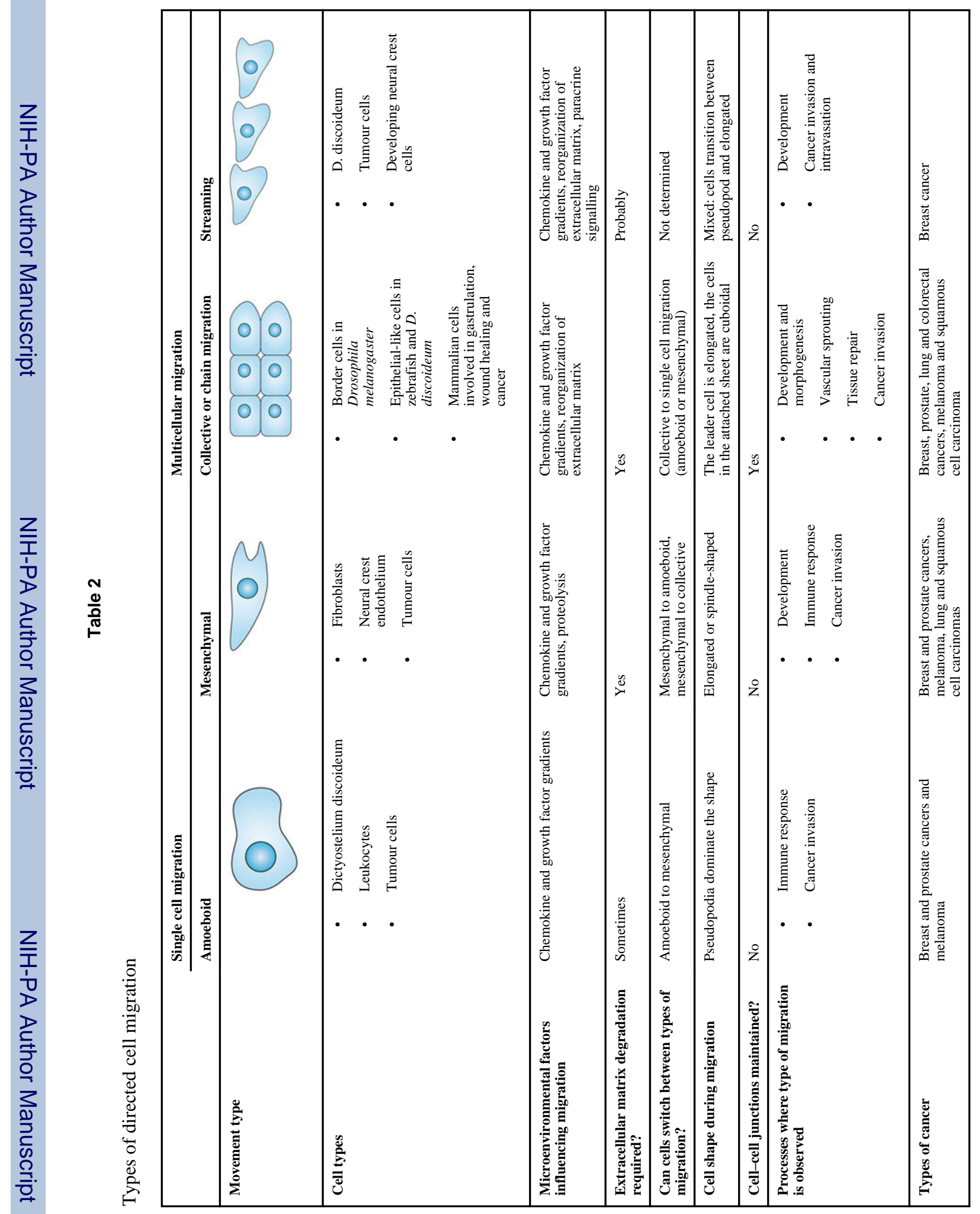

Nat Rev Cancer. Author manuscript; available in PMC 2014 May 22. 


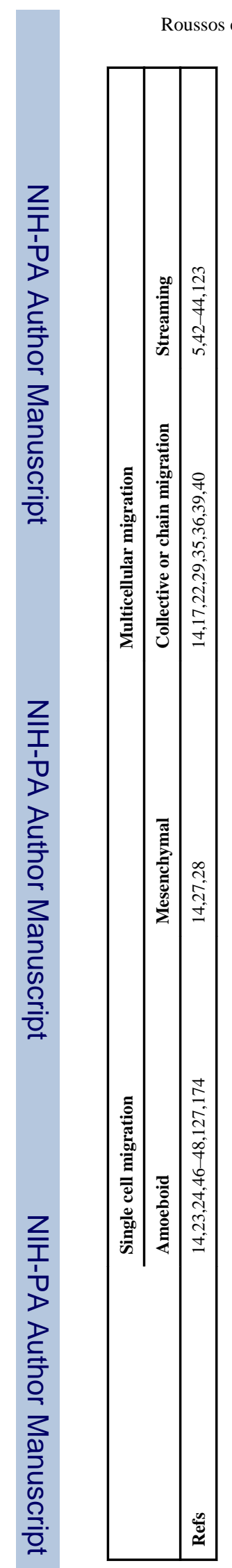

Nat Rev Cancer. Author manuscript; available in PMC 2014 May 22. 


\section{Table 3}

\section{Methodologies for studying cell migration in cancer}

\begin{tabular}{|c|c|c|}
\hline & Advantages & Disadvantages \\
\hline In vitro methods & $\begin{array}{l}\text { Users can add desired growth factors and evaluate chemotaxis } \\
\text { through a chemoattractant gradient }\end{array}$ & $\begin{array}{l}\text { No tumour microenvironment: these systems } \\
\text { lack a vasculature, the normal transport of } \\
\text { small molecules, host immune responses and } \\
\text { other cell-cell interactions }\end{array}$ \\
\hline $2 \mathrm{D}$ chemotaxis assays $*$ & $\begin{array}{l}\text { - A true measure of chemotaxis towards a source (or } \\
\text { in a defined gradient) of a chemoattractant } \\
\text { An ability to quantify directionality and molecular } \\
\text { asymmetry parameters }\end{array}$ & Requires a high skill level and can be tedious \\
\hline $\begin{array}{l}\text { Transwell assay (Boyden } \\
\text { chamber) }\end{array}$ & $\begin{array}{ll}\text { - } & \text { Ease of analysis } \\
\text { - } & \text { Extracellular matrix components can be added }\end{array}$ & $\begin{array}{l}\text { - Low resolution } \\
\text { - } \quad \begin{array}{l}\text { May not always measure } \\
\text { chemotaxis }\end{array}\end{array}$ \\
\hline 3D invasion ${ }^{19}$ & $\begin{array}{l}\text { - Cells must follow a chemotactic gradient through } \\
\text { the matrix } \\
\text { - Cells are embedded in a matrix (which is a better } \\
\text { mimic of the stromal microenvironment) } \\
\text { - When tumour cells are combined with other cell } \\
\text { types, migration in vivo can be mimicked } \\
\text { - Imaging is possible }\end{array}$ & No control of growth factor gradients \\
\hline Wound healing & $\begin{array}{l}\text { - } \quad \text { Ease of imaging and analysis } \\
\text { - } \quad \text { A defined direction of cell movement }\end{array}$ & $\begin{array}{l}\text { - } \quad \begin{array}{l}\text { Slow movement of cells in an } \\
\text { artificial space }\end{array} \\
\text { - } \quad \text { Not a measure of true chemotaxis }\end{array}$ \\
\hline $3 D$ culture $^{16}$ & $\begin{array}{l}\text { - Cells are embedded in a matrix (which is a better } \\
\text { mimic of the stromal microenvironment) } \\
\text { - When tumour cells are combined with other cell } \\
\text { types, the structure of an organ can be mimicked }\end{array}$ & $\begin{array}{l}\text { - Partial representation of the tumour } \\
\text { microenvironment } \\
\text { - } \begin{array}{l}\text { Only mimics static or short-term } \\
\text { conditions }\end{array}\end{array}$ \\
\hline In vivo methods & An accurate representation of the tumour microenvironment & $\begin{array}{l}\text { - Requires special training and } \\
\text { equipment } \\
\text { The interpretation of results is } \\
\text { complicated by the presence of } \\
\text { multiple cell types }\end{array}$ \\
\hline In vivo invasion assay & $\begin{array}{l}\text { Migration in response to chemoattractants in vivo can be } \\
\text { determined }\end{array}$ & \\
\hline Intravital imaging & $\begin{array}{l}\text { - } \quad \begin{array}{l}\text { Physiological cell movement can rapidly be } \\
\text { visualized }\end{array} \\
\text { - } \quad \begin{array}{l}\text { An opportunity to observe tumour cells progress } \\
\text { through steps of dissemination in real time }\end{array}\end{array}$ & Expensive \\
\hline
\end{tabular}

2D, two-dimensional; 3D, three-dimensional.

2D chemotaxis assays include the pipette-following assay, the Dunn chamber, the Zigmond chamber and the Soon chamber. 